\title{
Present State and Prospects of Ice Sheet and Glacier Modelling
}

\section{Review Article}

Author(s):

Blatter, Heinz; Greve, Ralf; Abe-Ouchi, Ayako

Publication date:

2011-06-01

Permanent link:

https://doi.org/10.3929/ethz-b-000159870

Rights / license:

In Copyright - Non-Commercial Use Permitted

Originally published in:

Surveys in Geophysics 32(4-5), https://doi.org/10.1007/s10712-011-9128-0 


\title{
Present State and Prospects of Ice Sheet and Glacier Modelling
}

\author{
Heinz Blatter • Ralf Greve • Ayako Abe-Ouchi
}

Received: 14 October 2010/Accepted: 12 May 2011/Published online: 1 June 2011

(C) Springer Science+Business Media B.V. 2011

\begin{abstract}
Since the late 1970s, numerical modelling has become established as an important technique for the understanding of ice sheet and glacier dynamics, and several models have been developed over the years. Ice sheet models are particularly relevant for predicting the possible response of ice sheets to climate change. Recent observations suggest that ice dynamics could play a crucial role for the contribution of ice sheets to future sea level rise under global warming conditions, and the need for further research into the matter was explicitly stated in the Fourth Assessment Report (AR4) of the United Nations Intergovernmental Panel on Climate Change (IPCC). In this paper, we review the state of the art and current problems of ice sheet and glacier modelling. An outline of the underlying theory is given, and crucial processes (basal sliding, calving, interaction with the solid Earth) are discussed. We summarise recent progress in the development of ice sheet and glacier system models and their coupling to climate models, and point out directions for future work.
\end{abstract}

Keywords Glacier · Ice sheet · Numerical modeling

\footnotetext{
H. Blatter $(\bowtie)$

Institute for Atmospheric and Climate Science, ETH Zurich, Universitätstrasse 16, 8092 Zurich, Switzerland

e-mail: blatter@env.ethz.ch

R. Greve

Institute of Low Temperature Science, Hokkaido University, Kita-19, Nishi-8, Kita-ku, Sapporo 060-0819, Japan

e-mail: greve@lowtem.hokudai.ac.jp

\section{A. Abe-Ouchi}

Atmosphere and Ocean Research Institute, The University of Tokyo, 5-1-5 Kashiwanoha, Kashiwa 277-8568, Japan

e-mail: abeouchi@aori.u-tokyo.ac.jp
} 


\section{Introduction}

Ice sheets (with their attached ice shelves), ice caps and glaciers are an important dynamic part of the Earth's climate system on time scales of decades and more. Most of the terrestrial freshwater reserves are stored in these ice masses, and they amount to more than $60 \mathrm{~m}$ of sea level equivalent. Against the background of ongoing global warming, research into the behaviour of ice sheets and glaciers is of great relevance. Some basic observational data are summarised in Table 1.

In Chap. 10 ("Global Climate Projections") of the Fourth Assessment Report (AR4) of the United Nations Intergovernmental Panel on Climate Change (IPCC), an increase of the mean global sea level by $18-59 \mathrm{~cm}$ for the twentyfirst century is projected for the SRES (Special Report on Emissions Scenarios) marker scenarios (Meehl et al. 2007). The main causes are thermal expansion of ocean water and melting of glaciers and ice caps, and to a lesser extent changes of the surface mass balance of the Greenland and Antarctic ice sheets. However, recent observations suggest that ice flow dynamics could lead to significant additional sea level rise, as stated explicitly in the AR4: "Dynamical processes related to ice flow not included in current models but suggested by recent observations could increase the vulnerability of the ice sheets to warming, increasing future sea level rise. Understanding of these processes is limited and there is no consensus on their magnitude." (IPCC 2007). This illustrates the importance of ice sheet and glacier models, and further improvement of them, for assessing the impact of future climate change, and for that reason it is a very "hot topic".

Numerical models may be classified as process models (Fowler 2001) or explanatory models (Murray 2002) on the one hand, and system models (Fowler 2001) or numerical simulations (Murray 2002) on the other. The first are generally simplified models designed to focus specific processes. The latter are required to simulate the evolution of ice sheets in a given climate, as sketched in Fig. 1.

The large ice sheets constitute systems with complex interactions with bounding external systems such as the atmosphere, ocean and lithosphere. Smaller glaciers generally constitute a simpler system than the large ice sheets in terms of coupled external systems; however, the flow field is more demanding in terms of computational requirements.

The reason for this difference lies in the fact that the aspect ratio $\varepsilon$, ratio of vertical extent to horizontal extent of the ice mass, is of the order $\varepsilon=10^{-3}$ for large ice sheets, but $\varepsilon=10^{-1}$ for small glaciers. The shallowness of large ice sheets allows for a corresponding approximation that omits horizontal coupling. However, this shallow ice approximation has to be taken with caution if processes on smaller scales or with large horizontal gradients are considered, such as basal sliding/non-sliding transitions, rough bed topography or shear margins at ice sheet/ice stream transitions. The process aspect ratio $\varepsilon_{\mathrm{p}}$, ratio of local ice

Table 1 Ice inventory on the present-day Earth (Lemke et al. 2007; Bindoff et al. 2007)

\begin{tabular}{llll}
\hline & Glaciers and ice caps & Greenland ice sheet & Antarctic ice sheet (+ice shelves) \\
\hline Area $\left(10^{6} \mathrm{~km}^{2}\right)$ & $0.51-0.54$ & 1.7 & $12.3(+1.5)$ \\
Volume $\left(10^{6} \mathrm{~km}^{3}\right)$ & $0.05-0.13$ & 2.9 & $24.7(+0.7)$ \\
Sea level equivalent $(\mathrm{m})$ & $0.15-0.37$ & 7.3 & $56.6(+0)$ \\
Sea level rise & & & $0.21 \pm 0.35$ \\
$1993-2003\left(\mathrm{~mm} \mathrm{a}^{-1}\right)$ & $0.77 \pm 0.22$ & $0.21 \pm 0.07$ & 0.35 \\
\hline
\end{tabular}

Note the large contribution of glaciers and ice caps to current sea level rise despite their small volume 


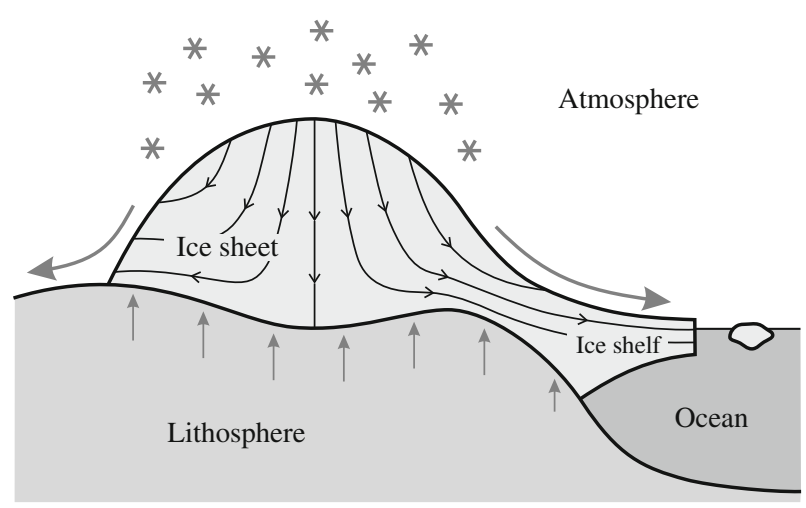

Fig. 1 Schematic of an ice sheet (with attached ice shelf) in the climate system. Gravity-driven glacial flow transports the ice from the central areas towards the margins. The ice sheet interacts with the atmosphere by precipitation (snowfall), surface temperature and surface melting. At the ice shelf-ocean interface, melting and freezing processes occur, and the ice shelf releases icebergs into the surrounding ocean ("calving"). Interaction with the lithosphere is by the geothermal heat flux entering the ice body from below, and by isostatic sinking and rebound. The vertical exaggeration factor is $200-500$

thickness to horizontal scale length of the corresponding process, is generally larger, $\varepsilon_{\mathrm{p}} \gg \varepsilon$, and thus the shallowness assumption no longer holds. A similar situation is given in models if the resolution of the horizontal grid becomes comparable to the local ice thickness. In this case, the grid aspect ratio $\varepsilon_{\mathrm{g}}$, ratio of local thickness to horizontal grid spacing, may be of comparable magnitude to $\varepsilon_{\mathrm{p}}$, and the shallowness assumption may also become unreliable.

Current ice sheet and glacier models are capable of simulating the continuous fields, velocity, temperature, surface and basal topography, to the correct magnitude. The accuracy, however, is critically affected by discontinuous processes such as sliding, calving, basal thermal and mechanical transitions, grounding lines, lateral margins. For long term simulations, the reliability of the model experiments also depends on the reliability of initial conditions and the transient boundary conditions.

Glacial systems may be considered stable if their change in volume is determined by the climatologically determined mass flux time scale, where the rate of volume changes is limited by the possible range of climatic accumulation and ablation rates. Internal discontinuous processes such as glacial hydraulics, sliding and calving, may lead to volume changes on much shorter time scales that may be referred to as catastrophic time scale. The latter processes will pose the greatest challenge for future ice sheet models, especially if the pressing question about the stability of the West Antarctic ice sheet must be answered.

This paper reviews the present state of ice sheet and glacier modelling and lists the present pressing questions concerning the dynamics of ice sheets and glaciers in the anticipated warming climate. The next section presents a summary of the Stokes problem of thermomechanically coupled ice flow, followed in Sect. 3 by a hierarchy of approximations presently in use. Discontinuities such as sliding, calving and the related issue of the stability of marine ice sheets are addressed in Sect. 4. Section 5 outlines the thermal and mechanical interaction of ice masses with the underlying solid Earth, which are relevant for the long term $\left(10^{5}\right.$ years) dynamics of ice sheets during glacial cycles. In Sect. 6 we describe system models of ice sheets and glaciers, discuss the coupling with climate models of various sophistication and the possibilities to test the reliability of quantitative predictions. The concluding Sect. 7 outlines the currently pressing questions and topics, and the activities required to address them. 


\section{Full Stokes Flow Problem}

Polycrystalline ice, as it occurs in ice sheets and glaciers, is described rheologically as an incompressible, nonlinear-viscous, heat-conducting fluid (e.g., Greve and Blatter 2009). The mass balance (continuity equation) thus reads

$$
\operatorname{div} \mathbf{v}=0,
$$

where $\mathbf{v}$ is the velocity. Integration over the vertical coordinate $z$ yields the evolution equation for the ice thickness $H(x, y, t)$ (horizontal coordinates $x, y$, time $t$ )

$$
\frac{\partial H}{\partial t}=-\operatorname{div} \mathbf{Q}+a_{\mathrm{s}}-a_{\mathrm{b}},
$$

where $\mathbf{Q}$ is the volume flux (vertically integrated horizontal velocity), and $a_{\mathrm{s}}$ and $a_{\mathrm{b}}$ are the mass balances at the surface (positive for supply) and the bottom (positive for loss), respectively. Equation (2) is the central evolution equation of glacier and ice sheet dynamics.

The deformation of ice is most commonly described by the nonlinear-viscous Glen flow law,

$$
\mathrm{D}=\frac{1}{2 \eta\left(T^{\prime}, \sigma_{\mathrm{e}}\right)} \mathrm{t}^{\mathrm{D}}
$$

where $\mathrm{D}=\operatorname{sym} \operatorname{grad} \mathbf{v}=\frac{1}{2}\left(\operatorname{grad} \mathbf{v}+(\operatorname{grad} \mathbf{v})^{T}\right)$ is the strain-rate (stretching) tensor, $\mathrm{t}^{\mathrm{D}}$ the deviatoric part of the Cauchy stress tensor $t$ and $\eta$ the shear viscosity. The fluidity (inverse viscosity) $1 / \eta$ factorises as

$$
\frac{1}{\eta\left(T^{\prime}, \sigma_{\mathrm{e}}\right)}=2 E A\left(T^{\prime}\right) f\left(\sigma_{\mathrm{e}}\right)
$$

where $T^{\prime}=T-T_{\mathrm{m}}+T_{0}$ is the temperature relative to the pressure melting point $T_{\mathrm{m}}$ $\left[T_{\mathrm{m}}=T_{0}-\beta p\right.$; melting temperature at standard pressure $T_{0}=273.15 \mathrm{~K}$, ClausiusClapeyron constant for air-saturated ice $\beta=9.8 \times 10^{-8} \mathrm{~K} \mathrm{~Pa}^{-1}$, pressure $p$ ], $A\left(T^{\prime}\right)$ the rate factor, $\sigma_{\mathrm{e}}=\sqrt{\frac{1}{2} \operatorname{tr}\left(\mathrm{t}^{\mathrm{D}}\right)^{2}}$ the effective stress (square root of the second invariant of $\mathrm{t}^{\mathrm{D}}$ ), $f\left(\sigma_{\mathrm{e}}\right)$ the creep function and $E$ the flow enhancement factor (see below).

The rate factor and creep function are usually expressed in the form of an Arrhenius law

$$
A\left(T^{\prime}\right)=A_{0} e^{-Q / R T^{\prime}}
$$

( $A_{0}$ : pre-exponential constant, $Q$ : activation energy, $R=8.314 \mathrm{~J} \mathrm{~mol}^{-1} \mathrm{~K}^{-1}$ : universal gas constant), and a power law,

$$
f\left(\sigma_{\mathrm{e}}\right)=\sigma_{\mathrm{e}}^{n-1}
$$

( $n$ : stress exponent), respectively (Table 2).

The inverse form of Glen's flow law (3) with the fluidity factorisation (4) and the power law (6) is

$$
\mathrm{t}^{\mathrm{D}}=2 \eta\left(T^{\prime}, d_{\mathrm{e}}\right) \mathrm{D}
$$

where $d_{\mathrm{e}}=\sqrt{\frac{1}{2} \operatorname{trD}^{2}}$ is the effective strain rate (square root of the second invariant of $\mathrm{D}$ ). The viscosity $\eta$ now factorises as 
Table 2 Parameters for the Arrhenius law (5) and the power law (6) (Paterson 1994; Greve and Blatter 2009)

\begin{tabular}{lll}
\hline Parameter & Value & \\
\hline Pre-exponential constant $\left(A_{0}\right)$ & $3.985 \times 10^{-13} \mathrm{~s}^{-1} \mathrm{~Pa}^{-3}$ & $\left(\right.$ for $\left.T^{\prime} \leq 263.15 \mathrm{~K}\right)$ \\
& $1.916 \times 10^{3} \mathrm{~s}^{-1} \mathrm{~Pa}^{-3}$ & $\left(\right.$ for $\left.T^{\prime}>263.15 \mathrm{~K}\right)$ \\
Activation energy $(Q)$ & $60 \mathrm{~kJ} \mathrm{~mol}^{-1}$ & $\left(\right.$ for $\left.T^{\prime} \leq 263.15 \mathrm{~K}\right)$ \\
Stress exponent $(n)$ & $139 \mathrm{~kJ} \mathrm{~mol}^{-1}$ & $\left(\right.$ for $\left.T^{\prime}>263.15 \mathrm{~K}\right)$ \\
\hline
\end{tabular}

$$
\eta\left(T^{\prime}, d_{\mathrm{e}}\right)=\frac{1}{2} E_{\mathrm{s}} B\left(T^{\prime}\right) d_{\mathrm{e}}^{-(1-1 / n)},
$$

where $B\left(T^{\prime}\right)=A\left(T^{\prime}\right)^{-1 / n}$ is the associated rate factor and $E_{\mathrm{s}}=E^{-1 / n}$ the stress enhancement factor.

The flow enhancement factor $E$ is equal to unity for secondary creep of pure, macroscopically isotropic polycrystalline ice (that is, the ice crystallites, a.k.a. grains, in the polycrystalline aggregate are randomly oriented). However, in regions of flowing ice sheets and glaciers with relatively high temperatures and/or stresses, tertiary creep may prevail, which goes along with the formation of an anisotropic fabric (non-uniform orientation distribution of the crystallites) favourable for the deformation regime at hand. A crude way of including this effect in the flow law is by multiplying the isotropic ice fluidity for secondary creep by a flow enhancement factor $E>1$ chosen in an ad-hoc fashion (e.g., Hooke 2005). More sophisticated models attempt at describing the evolution of anisotropy and its effect on ice deformation macroscopically (phenomenologically) or even on the microscopic scale. This leads to modified flow laws that either provide a flow enhancement factor depending on the anisotropic fabric, or replace the scalar relation (collinearity) between the tensors $t^{\mathrm{D}}$ and $\mathrm{D}$ by a tensorial one (e.g., Gagliardini et al. 2009; Greve and Blatter 2009).

Another potential limitation of Glen's flow law lies in the use of the power law (6) with a single stress exponent. This is justified by the simplifying assumption that, under the stress, strain rate and temperature conditions typically prevailing in glaciers and ice sheets, a single microscopic creep mechanism (dislocation creep) is dominant. In reality, ice deformation results from a combination of creep mechanisms with different stress exponents (e.g., Alley 1992; Langdon 1996; Goldsby and Kohlstedt 2001; Pettit and Waddington, 2003), and thus the creep function may be expressed as a sum of different powers of the effective stress. However, there is no consensus about which additional terms should be considered, and because of that Cuffey and Paterson (2010) recommend to stick to the simple power law (6) with $n=3$.

Scaling arguments show that, in contrast to atmosphere and ocean dynamics, the acceleration (inertia) term and the Coriolis force can be neglected in the momentum balance (e.g., Greve and Blatter 2009), so that it reduces to the force balance

$$
\operatorname{div} \mathbf{t}+\rho \mathbf{g}=\mathbf{0},
$$

where $\rho=910 \mathrm{~kg} \mathrm{~m}^{-3}$ is the density of ice and $\mathbf{g}$ the downward-pointing gravitational acceleration with the value $g=|\mathbf{g}|=9.81 \mathrm{~m} \mathrm{~s}^{-2}$. Combining the force balance (9) with the decomposition of the stress tensor 


$$
\mathrm{t}=-p \mathbf{l}+\mathrm{t}^{\mathrm{D}}
$$

(where $p$ is the pressure and I the unit tensor) and the flow law in the form of Eq. (7) yields the Stokes equation

$$
-\operatorname{grad} p+\operatorname{div}\left[\eta\left(T^{\prime}, d_{\mathrm{e}}\right)\left(\operatorname{grad} \mathbf{v}+(\operatorname{grad} \mathbf{v})^{\mathrm{T}}\right)\right]+\rho \mathbf{g}=\mathbf{0},
$$

which is the equation of motion for ice flow. Owing to the dependency of the viscosity $\eta$ on the velocity $\mathbf{v}$ via the effective strain rate $d_{\mathrm{e}}$, it is non-linear in $\mathbf{v}$.

From the general energy balance, Fourier's law of heat conduction

$$
\mathbf{q}=-\kappa(T) \operatorname{grad} T
$$

(q: heat flux, $\kappa$ : heat conductivity, see Table 3) and the caloric equation of state

$$
u=\int_{T_{0}}^{T} c(\bar{T}) \mathrm{d} \bar{T}
$$

( $u$ : specific internal energy, $c$ : specific heat, see Table 3), the temperature evolution equation

$$
\rho c\left(\frac{\partial T}{\partial t}+\mathbf{v} \cdot \operatorname{grad} T\right)=\operatorname{div}(\kappa \operatorname{grad} T)+4 \eta d_{\mathrm{e}}^{2}
$$

results. In this relation, the production term $\operatorname{tr}\left(\mathrm{t}^{\mathrm{D}} \cdot \mathrm{D}\right)=4 \eta d_{\mathrm{e}}^{2}$ is the strain heating, and volumetric heating due to radiation has been neglected.

The above equations need to be complemented by dynamic and thermodynamic boundary conditions at the surface and the bottom of the respective ice body. Since the surface is in contact with the atmosphere, it can be described in good approximation as stress-free, that is,

$$
\left.\mathrm{t} \cdot \mathbf{n}\right|_{\mathrm{s}}=\mathbf{0},
$$

where $\mathbf{n}$ is the outer unit normal vector, and the subscript " $\mathrm{s}$ " denotes the surface. The surface temperature $T_{\mathrm{s}}$ can be prescribed directly as a Dirichlet condition.

If the bottom is a sufficiently cold ice/rock or ice/sediment interface, the basal ice is essentially frozen to the underlying substrate, and a no-slip condition can be employed,

$$
\mathbf{v}_{\mathrm{b}}=\mathbf{0},
$$

where the subscript " $b$ " stands for the ice base. By contrast, if the basal temperature is at or close to the pressure melting point, basal sliding will occur and must be parameterised by an empirical sliding law. This will be discussed in more detail below (Sect. 4.1).

Table 3 Heat conductivity $\kappa$ and specific heat $c$ (Ritz 1987; Greve and Blatter 2009)

\begin{tabular}{ll}
\hline Parameter & Value \\
\hline Heat conductivity $(\kappa)$ & $9.828 e^{-0.0057 T[\mathrm{~K}]} \mathrm{W} \mathrm{m}^{-1} K^{-1}$ \\
Specific heat $(c)$ & $(146.3+7.253 T[\mathrm{~K}]) \mathrm{J} \mathrm{kg}^{-1} \mathrm{~K}^{-1}$ \\
\hline
\end{tabular}


As for the temperature field, let us assume that the geothermal heat flux that enters the ice body from below $\left(\mathbf{q}_{\text {geo }}\right)$ is known. Provided that the basal temperature is below the melting point and sliding is negligible, this yields the Neumann condition

$$
\left.\kappa \frac{\partial T}{\partial \mathbf{n}}\right|_{\mathrm{b}}=\mathbf{q}_{\mathrm{geo}},
$$

where $\mathbf{n}$ is again the outer unit normal vector. If the basal temperature is at pressure melting, this statement itself serves as a boundary condition,

$$
T_{\mathrm{b}}=\left(T_{\mathrm{m}}\right)_{\mathrm{b}}=T_{0}-\beta p_{\mathrm{b}},
$$

where $p_{\mathrm{b}}$ is the basal pressure.

For the case of floating ice shelves, the basal boundary conditions must be changed. Instead of the no-slip condition (16) or an empirical sliding law, a stress condition holds that equals the basal stress $\left.\mathrm{t} \cdot \mathbf{n}\right|_{\mathrm{b}}$ to the hydrostatic pressure of the sea water below the ice. The temperature conditions (17) or (18) are replaced by the statement that the basal temperature is equal to the freezing temperature of the sea water below the ice.

\section{Hierarchy of Approximations}

The full Stokes formulation is applicable to grounded ice sheets, ice caps and glaciers of all sizes as well as floating ice shelves. However, its numerical solution is demanding and computationally expensive. Therefore, it is desirable to derive suitable approximations that make use of the specific properties of the different systems. Specifically, the global geometric aspect ratio

$$
\varepsilon=\frac{[H]}{[L]}
$$

(where $[H]$ and $[L]$ are scales for the vertical and horizontal extents, respectively, of the ice body in question) can be used to truncate the Stokes equation in different order approximations. However, ice sheet and glacier dynamics are largely determined by other scale lengths such as smaller-scale variations in the bed topography or variations in the bed conditions, or even discontinuities. Thus, the applied approximation must be chosen to meet the requirements of the scales of the modelled processes. These global or local geometric aspect ratios, however, do not exclusively define the mode of operation of an ice mass, but the slip ratio, the ratio of the sliding velocity to the shear velocity, defines a second characteristic parameter:

$$
\varepsilon_{\mathrm{s}}=\frac{\left[U_{\mathrm{b}}\right]}{\left[U_{\mathrm{d}}\right]}
$$

(where $\left[U_{\mathrm{b}}\right]$ and $\left[U_{\mathrm{d}}\right]$ are scales for the basal sliding and internal deformation (shear) velocities, respectively). Of the two extreme cases, small aspect ratio and small slip ratio $\left(\varepsilon \ll 1, \varepsilon_{\mathrm{S}} \ll 1\right)$ are well described by the shallow ice approximation (Sect. 3.2), whereas small aspect ratio and large slip ratio $\left(\varepsilon \ll 1, \varepsilon_{\mathrm{s}} \gg 1\right)$ define a membrane flow, of which the shallow shelf approximation (Sect. 3.3) is a known example. 


\subsection{Higher Order Approximations}

The largest portion of terrestrial ice is locked in ice sheets and glaciers with a horizontal extent $[L]$ that is much larger than the vertical extent $[H]$. Thus, the geometric aspect ratio $\varepsilon \ll 1$, and this fact gives the motivation for a hierarchy of approximations. A detailed account of the approximations is given, for example, in Greve and Blatter (2009). Here, an overview is presented.

In Cartesian coordinates $(x, y, z)$, where $x, y$ and $z$ are the two horizontal and the vertical coordinates, respectively, the components of the force balance (9) are

$$
\begin{aligned}
& \frac{\partial t_{x x}}{\partial x}+\frac{\partial t_{x y}}{\partial y}+\frac{\partial t_{x z}}{\partial z}=0 \\
& \frac{\partial t_{x y}}{\partial x}+\frac{\partial t_{y y}}{\partial y}+\frac{\partial t_{y z}}{\partial z}=0 \\
& \frac{\partial t_{x z}}{\partial x}+\frac{\partial t_{y z}}{\partial y}+\frac{\partial t_{z z}}{\partial z}=\rho g
\end{aligned}
$$

where the $t_{\alpha \beta}$ are the corresponding components of the Cauchy stress tensor t. Omitting the small horizontal derivatives of the shear stresses in Eq. $(21)_{3}$ results in the hydrostatic equation

$$
t_{z z}=-\rho g(h-z) .
$$

Eliminating the non-deviatoric stress components yields the equations for the force balance written in deviatoric stress components $\left(t_{x x}^{\mathrm{D}}, t_{y y}^{\mathrm{D}}\right)$ only,

$$
\begin{aligned}
& 2 \frac{\partial t_{x x}^{\mathrm{D}}}{\partial x}+\frac{\partial t_{y y}^{\mathrm{D}}}{\partial x}+\frac{\partial t_{x y}}{\partial y}+\frac{\partial t_{x z}}{\partial z}=\rho g \frac{\partial h}{\partial x} \\
& 2 \frac{\partial t_{y y}^{\mathrm{D}}}{\partial y}+\frac{\partial t_{x x}^{\mathrm{D}}}{\partial y}+\frac{\partial t_{x y}}{\partial x}+\frac{\partial t_{y z}}{\partial z}=\rho g \frac{\partial h}{\partial y} .
\end{aligned}
$$

Substituting Glen's flow parameterisation, Eqs. (7) and (8), in the hydrostatic version of Eq. (21) results in two equations with the three velocity components $v_{x}, v_{y}$ and $v_{z}$,

$$
\begin{aligned}
& 4 \frac{\partial}{\partial x}\left(\eta \frac{\partial v_{x}}{\partial x}\right)+2 \frac{\partial}{\partial x}\left(\eta \frac{\partial v_{y}}{\partial y}\right)+\frac{\partial}{\partial y}\left(\eta\left(\frac{\partial v_{x}}{\partial y}+\frac{\partial v_{y}}{\partial x}\right)\right)+\frac{\partial}{\partial z}\left(\eta\left(\frac{\partial v_{x}}{\partial z}+\frac{\partial v_{z}}{\partial x}\right)\right)=\rho g \frac{\partial h}{\partial x} \\
& 4 \frac{\partial}{\partial y}\left(\eta \frac{\partial v_{y}}{\partial y}\right)+2 \frac{\partial}{\partial y}\left(\eta \frac{\partial v_{x}}{\partial x}\right)+\frac{\partial}{\partial x}\left(\eta\left(\frac{\partial v_{x}}{\partial y}+\frac{\partial v_{y}}{\partial x}\right)\right)+\frac{\partial}{\partial z}\left(\eta\left(\frac{\partial v_{y}}{\partial z}+\frac{\partial v_{z}}{\partial y}\right)\right)=\rho g \frac{\partial h}{\partial y} .
\end{aligned}
$$

Thus Eq. (24) must be solved simultaneously with the continuity equation (1). This hydrostatic approximation can be done for grounded ice sheets and floating ice shelves alike.

The next step of approximation is only valid for grounded ice sheets and glaciers, and applies the assumption that the vertical velocity component $v_{z}$ scales with geometric aspect ratio to the horizontal velocity components $v_{x}$ and $v_{y}$, thus the ratios of the horizontal gradients of $v_{z}$ to the vertical gradients of the horizontal velocity components are order $\varepsilon^{2}$ (Greve and Blatter 2009). This approximation is sometimes called first-order approximation (Blatter 1995) and is shown to 
reproduce the solution to the underlying Stokes equations to second order in the film's aspect ratio, regardless of the amount of slip at the base of the fluid (Schoof and Hindmarsh 2010).

With this assumption all terms in the hydrostatic approximation, Eq. (24), containing $v_{z}$ are omitted. The resulting two equations contain only the two horizontal velocity components $v_{x}$ and $v_{y}$, and can be solved independently of the continuity equation (1). There is no equivalent to this first-order approximation for floating ice shelves.

\subsection{Shallow Ice Approximation}

The above hydrostatic and first order approximations still consider horizontal derivatives of the velocity components, and thus consider all shear and deviatoric stress components. The shallow ice approximation (Hutter 1983; Morland 1984) omits the so called membrane stresses (Hindmarsh 2006b), and thus the deviatoric stresses $t_{x x}^{\mathrm{D}}$ and $t_{y y}^{\mathrm{D}}$, and the shear stress component in the vertical plane, $t_{x y}$. The separation of membrane stresses and horizontal shear stresses defines the two extremes, the shallow ice approximation (SIA) and the shallow shelf approximation (SSA). The SIA omits the membrane stresses due to the shallowness assumption and large friction at the bed, the SSA omits the horizontal shear stresses due to shallowness and mostly free basal slip.

The assumption that the deviatoric components $t_{x x}^{\mathrm{D}}$ and $t_{y y}^{\mathrm{D}}$, the shear stress component $t_{x y}$ and their gradients are negligibly small in Eq. (23) yields

$$
\begin{aligned}
& \frac{\partial t_{x z}}{\partial z}=\rho g \frac{\partial h}{\partial x}, \\
& \frac{\partial t_{y z}}{\partial z}=\rho g \frac{\partial h}{\partial y},
\end{aligned}
$$

and Glen's flow law reduces to

$$
\begin{aligned}
& \frac{\partial v_{x}}{\partial z}=2 A\left(T^{\prime}\right) \sigma_{\mathrm{e}}^{n-1} t_{x z}, \\
& \frac{\partial v_{y}}{\partial z}=2 A\left(T^{\prime}\right) \sigma_{\mathrm{e}}^{n-1} t_{y z} .
\end{aligned}
$$

This shallow ice approximation is widely used in present-day ice sheet models. Equations (25) and (26) reduce the dependencies of $t_{x z}, t_{y z}, v_{x}$ and $v_{y}$ to the depth below the ice surface and the inclination of the ice surface in the respective directions. The equations can be integrated such that the velocity components can be computed by quadratures,

$$
\begin{aligned}
& v_{x}=v_{\mathrm{b} x}-2(\rho g)^{n}|\operatorname{grad} h|^{n-1} \frac{\partial h}{\partial x} \int_{b}^{z} A\left(T^{\prime}\right)(h-\bar{z})^{n} \mathrm{~d} \bar{z}, \\
& v_{y}=v_{\mathrm{b} y}-2(\rho g)^{n}|\operatorname{grad} h|^{n-1} \frac{\partial h}{\partial y} \int_{b}^{z} A\left(T^{\prime}\right)(h-\bar{z})^{n} \mathrm{~d} \bar{z},
\end{aligned}
$$

where $v_{\mathrm{bx}}$ and $v_{\mathrm{by}}$ are the respective velocities at the ice base. 


\subsection{Shallow Shelf Approximation}

For shallow ice shelves, the hydrostatic approximation follow the same arguments as those for the ice sheet flow and is also given by Eq. (24). The shallow shelf approximation (Morland 1987; Weis et al. 1999) assumes that a plug flow (very large slip ratio) approximates the velocity field closely in the membrane-type situation with almost vanishing shear tractions at both the upper and lower boundary of the plate,

$$
\frac{\partial v_{x}}{\partial z} \approx 0, \quad \frac{\partial v_{y}}{\partial z} \approx 0
$$

With these assumptions, the vertically integrated force balance equation (23) becomes

$$
\begin{aligned}
& 4 \frac{\partial}{\partial x}\left(\bar{\eta} \frac{\partial v_{x}}{\partial x}\right)+2 \frac{\partial}{\partial x}\left(\bar{\eta} \frac{\partial v_{y}}{\partial y}\right)+\frac{\partial}{\partial y}\left(\bar{\eta}\left(\frac{\partial v_{x}}{\partial y}+\frac{\partial v_{y}}{\partial x}\right)\right)=\rho g H \frac{\partial h}{\partial x} \\
& 4 \frac{\partial}{\partial y}\left(\bar{\eta} \frac{\partial v_{y}}{\partial y}\right)+2 \frac{\partial}{\partial y}\left(\bar{\eta} \frac{\partial v_{x}}{\partial x}\right)+\frac{\partial}{\partial x}\left(\bar{\eta}\left(\frac{\partial v_{x}}{\partial y}+\frac{\partial v_{y}}{\partial x}\right)\right)=\rho g H \frac{\partial h}{\partial y}
\end{aligned}
$$

where $\bar{\eta}$ is the vertically integrated viscosity of the ice and $H$ the local ice thickness. A detailed account of the derivation of these equations is given, for example, in Greve and Blatter (2009). Equation (29) is not incompressible in the horizontal plane since vertical ice flow determines the changes of the thickness of the ice plate. These equations must be complemented by the mass continuity equation and boundary conditions at the upper and lower surface, at the grounding line and at the calving front. The shallow shelf approximation allows for a simple formulation of the contact problem at the grounding line by using the floating condition.

\subsection{Accuracy of Approximations}

Approximations are mostly motivated by the limitations of computing power or the availability of efficient, stable and accurate numerical algorithms to solve the system of generally non-linear equations in question. The definition of the accuracy of approximations is essentially defined by the purpose of the model, either simulation (system) models or explanatory models (Fowler 2001). The primary goal of most system models is the computation of the evolution of the distributed ice thickness; thus the accuracy of the ice flow is most essential. In three-dimensional models, the ice flow ( $\mathbf{Q}$ in Eq. 2) is computed by integration of the vertical profiles of the horizontal velocity component, whereas in vertically integrated models, the ice flow is a direct result of the vertically integrated model equations and the details of the velocity field are not explicitly computed. The determination of the accuracy of the latter models and their predictive power is thus more difficult.

In this section, we do not consider the verification of the numerical schemes. Considering the accuracy of approximations, the focus lies on a comparison of approximations to an exact solution of the equations such as the full Stokes equation. It must be ensured that in such a comparison neither the approximation nor the exact solution are polluted by significant errors in the numerical solutions.

Several studies investigated the accuracy of approximations of the Stokes equation at a range of wavelengths of the perturbations (Hindmarsh 2004, 2006a, b; Gudmundsson 2008; Schoof and Hindmarsh 2010); however, thus far only for isothermal ice flow. Since most of the approximations in consideration exploit the shallowness of the ice masses, the 
approximations should be considered an expansion of the Stokes equations in terms of the global geometric aspect ratio.

The results of Hindmarsh $(2004,2006 a)$ and Gudmundsson (2003) show a clear deviation of all approximations from the full Stokes solutions for shorter wavelength perturbations. The shallow ice approximation apparently starts to deviate from Stokes solutions at wavelengths shorter than $10^{2}$ to $10^{1}$, where the unit is given by the local ice thickness. Higher order solutions start to deviate at wavelengths below 5 to 10. This fact requires careful analysis of model results if dynamical or geometrical patterns of corresponding small scales are to be resolved. The possible accuracy is thus not only given by the global geometric aspect ratio $\varepsilon$, but, in realistic glacial systems, as well by local aspects ratios defined by local conditions. This may be expected to become a concern in shallow ice models if the resolution of horizontal grids is increased, such that the grid aspect ratio (ratio of vertical resolution to horizontal resolution) becomes substantially larger than the global geometric aspect ratio.

\section{Discontinuous Processes}

\subsection{Basal Sliding}

One difficulty in ice sheet modelling is the large range of possible sliding velocities such as between no sliding conditions at cold bases through slow sliding in the normal ice flow mode to fast sliding in ice streams. Basal friction may depend on largely different basal conditions such as rough hard beds to smoother sediment beds, or even perfect lubrication over subglacial lakes. Different types of sliding parameterisations stem from different underlying physical models of the sliding process itself; thus it is likely that one single sliding paramterisation may not be adequate for modelling the entire ice sheet.

The Weertman-type sliding parameterisation (Weertman 1957, 1964, 1971) is based on the assumption that the sole of the ice slides frictionlessly over a rough bed with a roughness with a wavelength considerably smaller than the local ice thickness. Thus, the sliding is described as the spatial mean velocity of the ice over a fictitious basal plane, averaged over a spatial area considerably larger than the roughness elements. This mean sliding velocity is determined by the resistance of the mean bed induced by the deformation of the ice across and around the roughness elements (Hutter 1983). The resulting resistance relates the mean sliding velocity to a power of the mean basal shear traction as can be anticipated from dimensional analysis (Gudmundsson 1994a; Greve and Blatter 2009) or determined by numerical modelling applying the Stokes equation for a fluid flowing over a wavy bed (Gudmundsson 1994a, b),

$$
v_{\mathrm{b}}=C_{1} \tau_{\mathrm{b}}^{n}
$$

where $C_{1}$ is a parameter defined by the roughness. The roughness can be modified by pressurised water at the bed such that the ice separates from the bed and sees a smaller effective amplitude of roughness, thus

$$
v_{\mathrm{b}}=C_{2} \frac{\tau_{\mathrm{b}}^{n}}{p_{\mathrm{eff}}} .
$$

where the effective pressure $p_{\mathrm{eff}}=p_{\mathrm{b}}-p_{\mathrm{w}}$ is defined by the difference of the basal hydrostatic pressure $p_{\mathrm{b}}$ of the ice and the water pressure $p_{\mathrm{w}}$ in the basal hydraulic system, 
and $C_{2}$ is a tunable coefficient. The direction of the basal velocity vector is always parallel to the basal shear traction, i.e., to the tangential component of the stress vector at the base.

Such Weertman-type sliding parameterisation has been implemented in many ice flow models of different approximations, in particular in shallow ice sheet models. The shallowness assumption implies that the stress field is a function of the local geometry alone and the velocity field additionally depends on the local temperature profile. Thus, sliding does not feedback on these fields except weakly through the slowly varying temperature field and the evolving geometry and its influence on the driving stress.

The fact that sliding in a SIA model does not feedback to the local nor the neighbouring stress profiles implies a singularity at the bed position where the criterion from non-sliding switches to sliding or vice versa, e.g., where the basal temperature has a cold/temperate transition (Fowler 2001). Stress only remains bounded if the velocity is continuous, which is a necessary condition for obvious reasons, and the second derivative of the horizontal velocity components with respect to the horizontal coordinates is finite (Blatter 1995). In numerical shallow ice sheet models, this singularity is hidden in the discretisation grids (Bueler and Brown 2009), especially at low resolution. With increasing computing power, higher resolution models become feasible and this issue may become a problem of accuracy and stability if processes with large gradients in the fields are resolved.

The Weertman-type sliding parameterisation has been implemented in higher order and full Stokes flow models in various ways. Direct implementations of the sliding parameterisation have been implemented through the discretisation scheme for basal grid point or mesh cells (Jouvet et al. 2009). One possibility is the inclusion of a homogeneous deforming shallow layer at the bottom of the ice, with no sliding between the ice sole and the layer and no sliding between the layer and the underlying bed (Vieli et al. 2001). The resulting relation between the tangential velocity component and the shear traction at the ice sole depends on the assumed rheology of the shallow layer. The Weertman-type power law with exponent $n$ results if a power law stress strain-rate relation with exponent $n$ for the layer is applied (Vieli et al. 2001; Greve and Blatter 2009).

In the above shallow layer implementation for sliding, the layer only shears in the horizontal plane; however, stress coupling in the horizontal direction is not included. If the shallow layer sliding model is coupled to higher order and full Stokes models, the membrane stresses are handled internally in the flow domain and the sliding parameterisation only handles the local stress strain-rate relation. If this sliding implementation is coupled to a SIA ice sheet model, it can not feedback to its shear velocity or handle the horizontal stress coupling.

A hybrid scheme is proposed by Bueler and Brown (2009) by implementing a similar idea for models in the shallow ice approximation: the ice sheet model yields the driving stress, a basal thin layer model handles the resistive basal shear stress, $\mathbf{t}_{\mathrm{b}}$, and a membrane balances the driving stress and the shear stress. To introduce the shallow shelf approximation as a sliding parameterisation, the shear stress is added to the right side of Eq. (29). The basal shear stress $\mathbf{t}_{\mathrm{b}}$ must be parameterised by a flow model for the basal thin layer corresponding to the envisaged basal sliding, and can depend on various physical quantities such as yield stress or water pressure in the layer.

This sliding parameterization does not feedback on the shear velocity in the local vertical profile of the shallow ice model. High sliding velocity corresponds to low friction and consequently to low basal shear stress. A weighted average of the velocities of the three-dimensional non-sliding shallow ice approximation and the velocities in the membrane was suggested by Bueler and Brown (2009) to consider the influence of basal sliding conditions on the velocity profile. However, the shallow ice approximation gives no 
information on the weighting factor, except for non slip conditions the weight starts at one for the shear velocity and zero for sliding, and goes to zero for the shear velocity and to one for sliding for very large basal velocities. This scheme also avoids problems associated with the singularity at slip/no-slip transitions mentioned above and it allows for handling large ranges of sliding velocities as demonstrated with the Parallel Ice Sheet Model Greenland model for ice streams (Bueler et al. 2010).

Sliding remains a critical issue. One reason is the difficulty in observing sliding and the basal conditions directly. A second reason is that sliding can be highly variable on short temporal and spatial scales. Furthermore, sliding velocities can not be determined on a spatial resolution better than about one to two local ice thicknesses for objective reasons by inverse methods using surface observations (Bahr et al. 1994; Truffer 2004).

\subsection{Calving}

On the Greenland ice sheet, calving accounts to about $47 \%$ of the total annual mass loss besides surface and bottom melt (Ohmura 2010). The corresponding number seems to be somewhat larger for Antarctica but is more difficult to estimate. Calving is a process which is not directly coupled to the actual climatic conditions and may lead to mass loss on much shorter time scales than ablation through climate controlled melt. As a discontinuous process, calving is difficult to quantify in numerical models that can not resolve its temporal and spatial scales.

\subsubsection{Grounded Ice}

Glaciers may calve into freshwater lakes and into sea water. Due to the difference in the densities of fresh and salty water, calving may be slightly different due to processes such as frontal melt and convection in the water in front of the ice cliff. Especially glaciers with mostly temperate basal ice are resting entirely, including the calving front, on the solid bed.

A few grounded calving fronts have been observed over time periods of decades, such as Columbia Glacier, Alaska (Krimmel 2001) and Hansbreen, Spitsbergen (Vieli et al. 2002). These observations clearly reveal a connection between the calving rate and resulting advance or retreat rates and the bed geometry (Van der Veen 1996). Front positions on beds sloping downwards in the flow direction seem to be stable whereas, on upsloping beds, stable front positions may not be possible. One process that may explain this behaviour is buoyancy, which directly depends on the water depth at the calving front. However, buoyancy requires that the pressure of the sea water is transmitted below the ice at least to some distance, which is perhaps only possible over distributed areas if the glacier bed is temperate.

Model studies could reproduce these patterns of retreating and advancing grounded calving tongues over an undulating bed by applying a calving parameterisation related to an ice thickness above floatation (Vieli et al. 2000, 2001). For Hansbreen, Spitsbergen, the time scales of the modelled fast retreats over bed depressions correspond well with observed retreat rates (Vieli et al. 2002).

Nick et al. (2007) applied a simplified model to Columbia Glacier, Alaska, and confirmed the importance of bed geometry for calving rates, especially if moraines modify the bed topography near the calving front. Their results indicate that stable equilibria may not exist on backsloping beds; however, the results are not entirely conclusive.

Tidewater and freshwater glaciers may not become floating if only buoyancy would control the calving rate, such as applied in models with simple buoyancy related calving 
parameterisations. A different approach has been taken by Benn et al. (2007). Following Nye (1957), the crevasse depths is parameterised with a depth

where the longitudinal tensile strain rate exactly balances creep closure resulting from ice overburden pressure (Benn et al. 2007)

and the calving front is located where the crevasse depth reaches sea level. This may happen for both grounded and floating conditions.

The above model approaches to handle calving must be considered parameterisations. A novel suggestion to model calving may be given by damage mechanics (Pralong et al. 2003, 2006; Pralong and Funk 2005), which may be included into full Stokes flow models. Damage denotes a continuous field that is defined by source and sink terms related to the stress field, as formulated by Pralong and Funk (2005):

The damage is described by a state variable $\mathrm{D}$ (called damage variable), which is defined through the change in rheological properties with increasing material deterioration (Kachanov 1999). The value of the damage variable is therefore determined with regard to the effects of the micro-defects on the mesoscopic response of the material (Krajcinovic 1996).

The magnitude of the damage defines the strength or weakness of the ice, a highly damaged zone is much less viscous and the density is small. Sources for damage are given by large stresses, sinks must be parameterised by additional conditions, which may be difficult to identify, to let ice recover to normal strength. Two-dimensional flow models including damage were successfully applied to crevasse opening and triggering ice avalanches (Pralong et al. 2003; Pralong and Funk 2005). One version of a two-dimensional model including the acceleration term in the force balance qualitatively reproduced the calving of a grounded terminus. When the viscosity in the damaged zone becomes small enough, the system becomes unstable and the calving piece of ice slides rapidly over the damaged zone (Jouvet 2010).

\subsubsection{Floating Ice}

In most ice sheet models, the floating ice shelves are treated with the shallow shelf approximation; however, the boundary conditions at the margins, (a) grounding line, (b) coastline, (c) ice rise margins and (d) calving front (Weis et al. 1999) require treatment that is beyond the possibilities of the approximation. In particular, the calving front is sometimes not treated explicitly and the ice shelf extends to the margin of the numerical grid (Huybrechts 1990) or the ice shelf is cut off at a given ice thickness (Ritz et al. 2001) or at the grounding line (Saito and Abe-Ouchi 2004; PISM, http://www.pism-docs.org/).

Ice shelves are the parts of ice sheets where the contact to ocean water establishes an important boundary that may control the dynamics and the stability of the larger glacial system. In view of this complexity, existing ice shelf models must be considered as process models. The ice shelf-ocean coupling involves not only the floating condition but may also contribute substantially to the mass budget at the ice base (Nøst and Foldvik 1994; Grosfeld and Sandhäger 2004). Depending on thermal conditions and flow of ocean water, the water-ice interaction may lead to both melting and freezing at the base. Melting at the ice base produces a layer of fresh water that may flow upwards towards the margin and become supercooled and form ice platelets with decreasing pressure. This ice may accumulate at the base and thus further contribute to the accumulation. The increased buoyancy due to the ice platelets in the ocean water, an ice shelf plume may form which feeds back to 
the ocean circulation beneath the shelf (Lewis and Perkin 1986; Jenkins and Bombosch 1995; Smedsrud and Jenkins 2004).

Both grounded and floating calving thus far can only be handled by parameterisation. The primary problem lies in the fact that stress fields computed in models are only given at low resolution compared with the small scales on which the processes leading to calving work. This is especially true in shelves where fractures are triggered locally but progress over large distances and calve off large tabular ice bergs.

The Benn et al. (2007) calving law allows for both grounded and floating calving and the transition between both. Otero et al. (2010) extended the Benn et al. (2007) calving law to a three-dimensional glacier. They identified some weaknesses in the model related to basal sliding parameterisation and the parameterisation of crevasse depths; however, they also identified some possible improvement such as assuming a partial filling of crevasses with water, and the balancing at the crevasse bottom of the opening tensile deviatoric stress with the closing ice overburden pressure.

Several other observed processes may have to be considered in realistic floating calving models. Calving of tabular icebergs seems to be closely related to rift systems (Joughin and MacAyeal 2005), where rift widening seems to progress gradually but rift length increases episodically. A conceptual model, also related to rift formation, proposes rapid ice shelf disintegration due to bending stresses induced by calving along the shelf terminus (Scambos et al. 2009). The deepening of the new crevasses formed by the bending stress after the previous calving event is further supported by increased hydrostatic pressure due to increased amount of water in the crevasse (hydro-fracture) in a warming climate. Enhanced bottom melting in a warming climate may also carve substantial channels in the bottom of the ice shelf, thus may affect the mechanical strength of the shelf and support breaking of the ice (Rignot and Steffen 2008).

\subsection{Stability of Marine Ice Sheets}

Marine ice sheets or glaciers are in close contact with ocean water and are thus more exposed to possible instabilities than land based grounded glaciers. One possible situation of instability is related to grounding calving termini on reversely tilted glacier beds, where seemingly no stable equilibrium positions are possible (Vieli et al. 2001; 2002; Nick et al. 2007). Closely related to this is the situation of floating glacier tongues with a grounding line on a reversely tilted bed (Schoof 2007); however, this is under the assumption that the floating part only weakly feeds back on the dynamics of the grounding line. These results were found by using two-dimensional flowline models and do not consider other factors to be influencing the stability. There are indications that this partly applies to three-dimensional valley glaciers, e.g., Hansbreen, Spitsbergen (Vieli et al. 2002) and Columbia Glacier (Nick et al. 2007). However, Nick et al. (2010) show that stable equilibria may exist even if a grounded calving tongue or a grounding line lies on backsloping beds, if calving is determined by crevassing at the surface and at the bed, and not directly by buoyancy.

Thus far, the applied and presented full Stokes models of the ice sheet/ice shelf transition are two-dimensional (flowline) process models. Durand et al. (2009a) confirmed the hysteresis of Schoof (2007) in the grounding line dynamics; however, they also found a sensitivity of the grounding line position to the chosen horizontal grid resolution (Durand et al. 2009b), possibly making adaptive grid resolution a requirement for the modelling of the grounding line position and stability in large scale system models of Antarctica (Vieli and Payne 2005; Gladstone et al. 2009). The addition of melting below ice shelves and the 
simulation of buttressing by including a lateral resistance to the force balances clearly demonstrate the strong influence of these additional factors to the grounding line dynamics (Walker et al. 2008; Goldberg et al. 2009; Gagliardini et al. 2010); however, also demonstrates the limitations of two-dimensional process models. They allow us to identify processes, such as basal melt, buttressing and basal flow conditions and topography, that are relevant for the dynamics and stability of marine ice sheets. For conclusive, quantitative and reliable predictions of the stability of West Antarctica, for example, considerably more complex models are required.

Large parts of the West Antarctic ice sheet are grounded well below sea level and laterally bounded by large floating ice shelves. This situation is certainly vulnerable to instabilities; however, despite the partly reverse tilt of the bed, additional features make it very difficult to conclusively judge the present day situation with respect to a possible runaway mass loss of the large ice shelves or even parts or the presently grounded West Antarctic ice sheet. Disintegration may mean break up of the floating parts of marine ice sheets as was observed in recent years on smaller ice shelves along the Antarctic peninsula. It may also mean that grounding lines move into critical regions where stable states are not possible. For large scale disintegration, both processes may have to work together such that floating parts break apart after grounding lines retreat inland, or vice versa, that ice shelf thinning due to bottom or surface melt or reduced advection leads to a migration of the grounding line into unstable positions. Thus, modelling of such breakup and retreat or collapse of marine ice sheets requires the treatment of these processes explicitly if a reliable prediction is to be obtained. The challenge is that these processes either act on small scales and must be treated by subgrid parameterisation (hydro-fracture, rift formation) or require the solution of the full equations without approximations, e.g., full Stokes for the force balance or plate bending stress (Scambos et al. 2009).

An additional feature that makes the interaction between ice sheet and ice shelf even more complex is the occurrence of ice streaming (Walker et al. 2009). Ice streams are dynamic systems, although their grounding lines seem to be relatively stable or moving only episodically between stable positions (Horgan and Anandakrishnan, 2006). A possible stabilising mechanism is the till deposition at the grounding line of ice streams (Anandakrishnan et al. 2007). There are also indications that ice streams are able to transmit changes in the floating part upstream on timescales of decades, i.e., more rapidly than at non-streaming parts (Payne et al. 2004). Thus the ice sheet/ocean coupling may become more important in ice streams. On the other hand, a shutdown of streaming may result from climatic warming, increased precipitation, resulting in larger advection rates (Verbitsky 2002). Thus, the response and stability of marine ice sheets in changing climates is not obvious, and

Continued measurement of the evolving flow field, geophysical efforts to define the fjord geometry more precisely, and improved understanding of ocean/fjord/ice interactions will all improve our collective ability to model this (marine ice sheet) and similar systems (Joughin et al. 2008).

\section{Interaction with the Solid Earth}

\subsection{Temperature Evolution in the Lithosphere}

In time-dependent scenarios, the thermal inertia of the lithosphere dampens temperature changes in the deeper parts of a glacier or an ice sheet significantly. In order to account for 
this effect, the temperature evolution in a thermal boundary layer of the lithosphere must be computed,

$$
\rho_{1} c_{1}\left(\frac{\partial T}{\partial t}+\mathbf{v} \cdot \operatorname{grad} T\right)=\operatorname{div}\left(\kappa_{1} \operatorname{grad} T\right),
$$

where $\rho_{1}$ is the density, $c_{1}$ the specific heat $\left(\rho_{1} c_{1} \sim 2,000-3,000 \mathrm{~kJ} \mathrm{~m}^{-3} \mathrm{~K}^{-1}\right)$ and $\kappa_{1}$ $\left(\sim 3 \mathrm{Wm}^{-1} \mathrm{~K}^{-1}\right)$ the heat conductivity of the lithospheric (crustal) material. This equation is similar to the temperature evolution equation (14) for ice; however, strain heating has been neglected. The horizontal component of the velocity $\mathbf{v}$ of the lithosphere is also negligible, whereas a vertical component arises from the displacement of the lithosphere due to glacial isostasy (see Sect. 5.2 below).

The thickness of the lithospheric thermal boundary layer to be considered depends on the time scale of imposed temperature changes at the surface. Ritz (1987) demonstrated that for climatological time scales $\leq 100 \mathrm{ka}$ a thickness of $2 \mathrm{~km}$ is sufficient. If Eq. (32) is solved together with Eq. (14), the geothermal heat flux (Eq. 17) must be prescribed at the bottom of the lithospheric thermal boundary layer rather than at the ice base. Instead, temperature continuity is assumed between the ice and the lithosphere.

\subsection{Glacial Isostasy}

Glacial isostasy describes the process of restoring gravitational equilibrium between the Earth's lithosphere and the underlying asthenosphere under the influence of temporally and spatially varying ice loads. As a consequence, the lithosphere suffers an essentially vertical displacement $w(x, y, t)$ with respect to its unloaded equilibrium position (Fig. 2).

This process can be described in great detail by sophisticated self-gravitating, spherical, visco-elastic multi-layer (SGVE) models of the Earth (e.g., Lambeck et al. 1990; Le Meur 1996; Thoma and Wolf 1999; Le Meur and Huybrechts 2001; Tarasov and Peltier, 2002). However, in typical ice sheet modelling applications, such a level of complexity is not required, and a simpler treatment is feasible that models the lithosphere as a thin elastic plate and the asthenosphere as a viscous fluid, parameterised by a time-lag constant ("elastic lithosphere/relaxing asthenosphere" or ELRA model; Le Meur and Huybrechts 1996).

In the ELRA model, the steady-state displacement $w_{\mathrm{ss}}$ of the lithosphere under the influence of the ice load $\rho g H$ (downward) and the buoyancy $\rho_{\mathrm{a}} g w_{\mathrm{ss}}$ (upward) is governed by the biharmonic equation

Fig. 2 Glacial isostasy: vertical displacement $w$ of the lithosphere (thickness $H_{l}$ ) due to a temporally and spatially varying ice load $\rho g H$. The dashed lines mark the top and bottom of the lithosphere in unloaded equilibrium

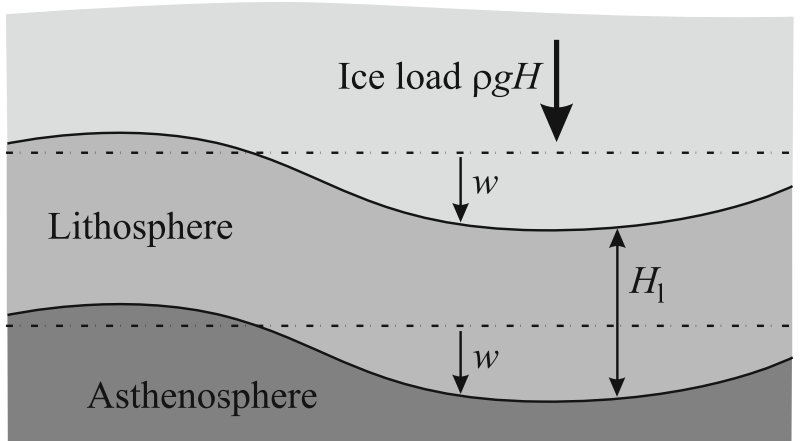




$$
K_{1} \Delta^{2} w_{\mathrm{ss}}+\rho_{\mathrm{a}} g w_{\mathrm{ss}}=\rho g H
$$

(e.g., Marguerre and Woernle 1969), where $K_{1}\left(\sim 10^{25} \mathrm{~N} \mathrm{~m}\right)$ is the flexural stiffness of the lithosphere and $\rho_{\mathrm{a}}=3,300 \mathrm{~kg} \mathrm{~m}^{-3}$ the density of the asthenosphere. The Green function $G$ of Eq. (33) is given by

$$
G(r)=G(x, \check{x}, y, \check{y})=-\frac{L_{\mathrm{r}}^{2}}{2 \pi K_{1}} \operatorname{kei}\left(\frac{r}{L_{\mathrm{r}}}\right),
$$

with

$$
r=\sqrt{(x-\check{x})^{2}+(y-\check{y})^{2}}, \quad L_{\mathrm{r}}=\left(\frac{K_{1}}{\rho_{\mathrm{a}} g}\right)^{1 / 4}
$$

(Brotchie and Silvester 1969). Here, $\operatorname{kei}(\cdot)$ is a Kelvin function of zero order, which can be derived from the general Bessel function, and whose values are tabulated in mathematical handbooks (e.g., Abramowitz and Stegun 1970). It is shown in Fig. 3.

The Green function (34) allows to construct the solution of the biharmonic equation (33) for a general distribution of the ice load by superposition,

$$
w_{\mathrm{ss}}(x, y, t)=\int_{A_{\mathrm{ice}}} \rho g H(\check{x}, \check{y}, t) G(x, \check{x}, y, \check{y}) \mathrm{d} \check{x} \mathrm{~d} \check{y},
$$

where $A_{\text {ice }}$ denotes the ice-covered area.

Due to the viscosity of the asthenosphere, the lithosphere cannot assume the steady-state displacement $w_{\mathrm{ss}}$ immediately. In the ELRA model, this is parameterised by the isostatic time lag $\tau_{\mathrm{a}}(\sim 3 \mathrm{ka})$, and the actual displacement $w(x, y, t)$ is determined by the simple relaxation equation

$$
\frac{\partial w}{\partial t}=-\frac{1}{\tau_{\mathrm{a}}}\left(w-w_{\mathrm{ss}}\right) .
$$

The radius of relative stiffness $L_{\mathrm{r}}$ has a value of $\sim 100 \mathrm{~km}$. This is much smaller than the typical horizontal extent of a large ice sheet like Antarctica or Greenland. Therefore, the elastic term in Eq. (33) is sometimes neglected, which leads to the local balance between ice load and buoyancy

$$
\rho_{\mathrm{a}} g w_{\mathrm{ss}}=\rho g H \quad \Rightarrow \quad w_{\mathrm{ss}}=\frac{\rho}{\rho_{\mathrm{a}}} H .
$$

In combination with the relaxation equation (37), this model is referred to as the local lithosphere/relaxing asthenosphere or LLRA model.

Fig. 3 The Kelvin function (normalised displacement of the elastic lithosphere under a point load)

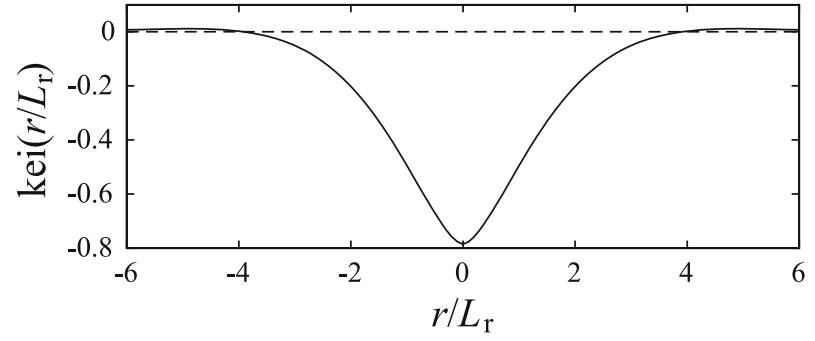


For ice caps like Vatnajökull or Austfonna, the horizontal extent is similar to $L_{\mathrm{r}}$, and the LLRA model cannot be used; the non-locality of the elastic lithosphere approach is then essential and must be accounted for. Glaciers are typically much smaller than $L_{\mathrm{r}}$, which leads to an extreme spreading of the isostatic displacement and renders it negligible. Thus isostasy need not be considered for glaciers.

\section{System Models}

\subsection{Ice Sheet Models}

Although glaciers may contribute more to sea level changes on time scales of decades, the ice sheets of Greenland and Antarctica may be more important on longer time scales and in terms of large catastrophic contributions.

To study ice sheet dynamics, models of various degrees of sophistication are required, depending on the specific questions. These questions may concern the understanding of glacial cycles, the present state of the ice sheet or the future of the ice sheets for a range of possible climate scenarios.

Although the flow field is quasi-stationary, thermal inertia and the evolution of the geometry, both the basal isostatic relaxation and the surface evolution, are truly transient with a wide range of temporal scales. The long memory of the ice sheet requires accurate initial conditions in addition to accurate history of the boundary conditions. Furthermore, the extent, surface altitude and surface conditions may feedback to the conditions above and below the ice sheet. This may make it necessary to couple ice sheet models to models of the solid Earth, ocean and atmosphere bounding systems. Since these systems act on largely different scales, especially time scales, the coupling must apply specific techniques to maintain realistic process physics and computability.

The prediction of the future evolution of, e.g., the Greenland ice sheet depends primarily on the assumed scenarios of the future climate but also on the initial (present) conditions to start the model run. Observations provide the accurate surface and bedrock topography and information from the existing ice cores provides additional data such as ice temperature and rheology at given locations. The three-dimensional fields of present-day temperature and viscosity of the ice sheet can only be obtained by numerical ice sheet models.

The thermo-mechanical processes are slow in comparison with the temporal and spatial variability of the climatic states of the atmosphere and ocean. The long memory, over more than one glacial cycle (Calov and Hutter 1996) requires a correspondingly long spin up run of the model to establish the present-day conditions. Thus far, two distinct methods to compute present-day initial conditions were applied, (1) simulations driven by temperature reconstructions based on ice cores, and (2) steady state simulations with present-day climate conditions (Rogozhina et al. 2011 and references therein). Since the present state cannot possibly be a steady state to the present or any other climate condition, it must necessarily deviate from any transient state obtained by method 1). Seemingly, the steady state temperatures are too high and the domain of basal and near-basal temperate ice is too large (Huybrechts, 1996; Greve 1997; 2000). Also the present-day conditions obtained by transient model runs for some time in the past may depend on the chosen past initial conditions, unless the integration time is long enough for the ice sheet to forget those initial conditions. This, however, may be a problem since the paleo-climate reconstructions needed for the boundary conditions lose accuracy and reliability with increasing age. 
Accurate initial conditions to start a model run for the next few millennia are crucial especially since basal thermal conditions determine whether there is sliding or non-sliding and large shearing of soft warmer ice or hard colder ice.

The problem becomes particularly serious if the evolution of ice sheets over the coming decades or few centuries must be predicted. Over this short time span, the initial conditions strongly influence the prognostic computations, and, if not accurate, produce poor predictions (Arthern and Gudmundsson 2010). To overcome this problem, combinations of observed data and model computations are applied, such as data assimilation techniques based on control methods (Vieli and Payne 2003; Vieli et al. 2006; Arthern and Hindmarsh 2006), or adjoint models that derive the sensitivities of ice sheets to boundary and initial conditions (Heimbach and Bugnion, 2009).

Three operational ice sheet models are currently available on the internet as free software:

- Glimmer-CISM (Community Ice Sheet Model, http://glimmer-cism.berlios.de/);

- PISM (Parallel Ice Sheet Model, http://www.pism-docs.org/);

- SICOPOLIS (SImulation COde for POLythermal Ice Sheets, http://sicopolis.greveweb.net/).

These models include three-dimensional coupling of temperature and velocity fields in the shallow ice approximation. They differ in the numerical grids and some numerical schemes, but also allow for various physical processes such as polythermal conditions (SICOPOLIS, PISM) or a novel type of sliding parameterisation (PISM). Glimmer-CISM is particularly designed to be interfaced to a range of global climate models. All three models are currently under rapid development, and in different stages towards implementation of higher-order dynamics (Sect. 3.1), ice shelf dynamics (Sect. 3.3) and discontinuous processes (Sect. 4). Figure 4 illustrates schematically the various components of the models.

\subsection{Coupling to Climate Models}

Glacial cycles constitute climate changes beyond the observed variations of the past few centuries. Thus, the reconstruction of the waxing and waning of the ice sheets is an essential component in studying the climate system, and, in particular, the dynamics of ice sheets. It is now well accepted that the Milankovitch cycles of orbital and rotational elements of the Earth play an essential role in the triggering and pacing of the growth and shrinkage of the ice sheets, especially in the northern hemisphere. However, a thorough understanding of internal processes and feedback mechanisms of the climate system is crucial to understand many details of the glacial cycles. It is thus necessary to couple, in some adequate way, a climate system model to a model of the ice sheets to capture the interactions between climate and ice sheets during entire glacial cycles. However, comprehensive global atmosphere ocean circulation models including sea ice and possible other sub-systems to handle $\mathrm{CO}_{2}$ fluxes, land albedo and aerosols are prohibitively expensive in computational requirements. Thus, the integration over glacial cycles is still far beyond the reach of computer capacity presently and possibly for quite some time in the future.

To circumvent this obstacle, a whole palette of simplified methods for direct and indirect coupling of ice sheet models to climate models has been proposed. Since threedimensional thermomechanically coupled ice sheet models can be run over several glacial cycles with present computers, the compromises always concern the climate models. Basically, three different types of approaches can be distinguished. 


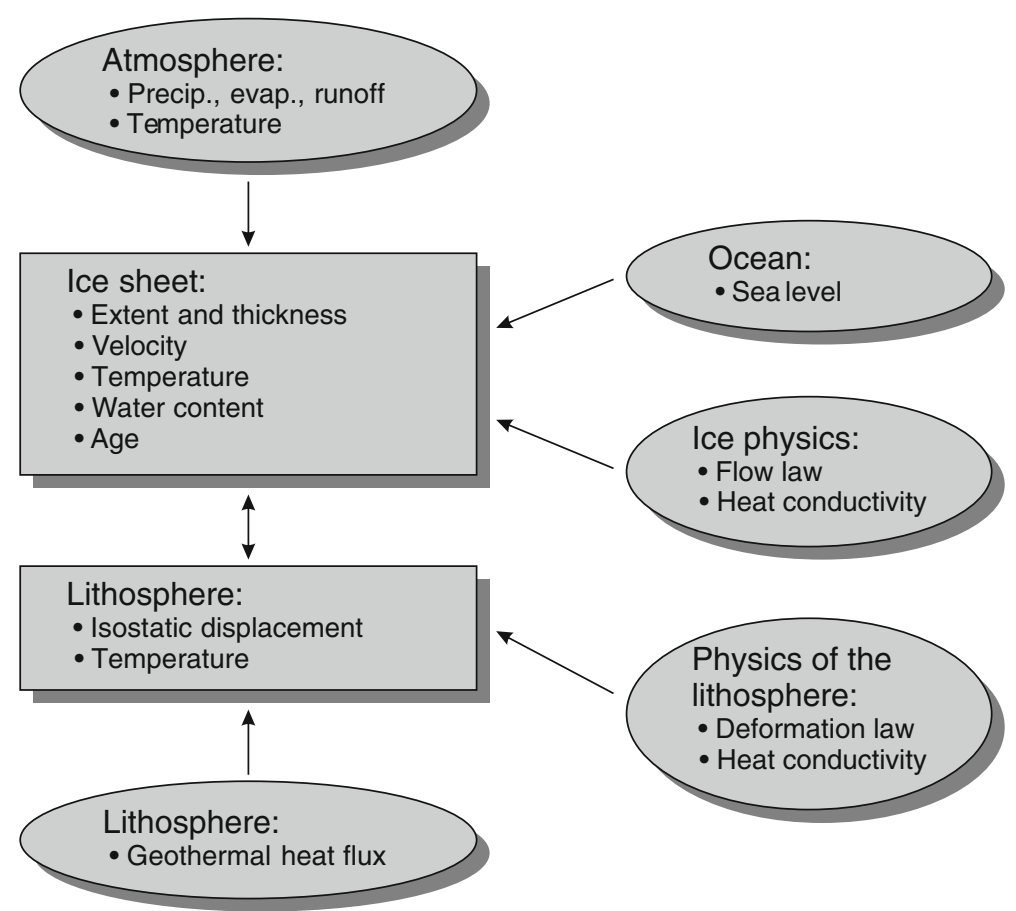

Fig. 4 Scheme of a modern, dynamic/thermodynamic ice sheet model. The rectangular boxes correspond to prognostic model components, the oval boxes to input quantities

The most commonly used approach uses the present-day observed climate and applies some perturbation to it derived from available proxy data such as isotopic composition and atmospheric greenhouse gas concentrations from ice cores (Ritz et al. 1997; Abe-Ouchi et al. 2007; and references therein).

A second approach couples ice sheet models to climate models reduced in dimension, resolution and physical processes. Recently, so called Earth Models of Intermediate Complexity (EMICs), see Clausen et al (2002), allow for long term climate simulations for a coarse zonal and sectorial resolution. The advantage of an EMIC is the possibility to couple several subsystems, such as the atmosphere, oceans, land surface types and energy and mass fluxes, atmospheric aerosols, and a comprehensive three-dimensional ice sheet model (Ganopolski et al. 2010). The low spatial resolution and limited physics, however, limit the possibility to take into account the feedback of variations in the ice sheet extent and altitude on the climate, in particular on atmospheric and oceanic circulation patterns.

A third possibility is the use of comprehensive three-dimensional global climate models, either atmosphere ocean general circulation models (AO-GCM) or atmosphere circulation models (A-GCM) with some idealised slab ocean. However, even at low spatial resolution, the computational requirement limits the time span to be modelled to few centuries. Therefore, time slices of a few decades for selected periods of glaciation extents, astronomical forcings or greenhouse gas concentrations may serve to parameterise climatic conditions, such as temperature and mass balance (Abe-Ouchi et al. 2007). Furthermore, A-GCM and AO-GCM experiments give the possibility to investigate the influence of the 
ice sheet to general patterns of the atmospheric circulation and storm tracks, and thus have an influence back to the mass balance and ice sheet dynamics.

In coupled modelling of the ice age cycles, input from climate models is commonly given at low spatial resolution compared with the resolution of ice sheet models. However, one should not reduce the resolution of ice sheet models because, depending on the scheme to advance the ice sheet margin, a minimal resolution of the ice sheet models must be applied to avoid a failure of properly advancing the margin (Abe-Ouchi and Blatter 1993). To better match the resolutions of climate and ice sheet models, regional climate models are a possibility, see e.g. Box et al. (2006).

In contrast to glacial cycles, future global warming scenarios typically encompass time scales of decades to centuries. As mentioned above, for such time scales the coupling of AO-GCMs with ice sheet models has become feasible (see, e.g., Vizcaíno et al 2008; Ridley et al. 2009). The ongoing increase in computer performance will certainly allow improvements in time span covered and model resolution in the near future.

\subsection{Testing Ice Sheet Models}

System models of ice sheets consist of a coupled set of non-linear differential equations with boundary conditions on mass, momentum and energy fluxes, and initial conditions of geometry and thermodynamic fields. The complexity of the system requires simplifications of physical processes and the system components, and the computation of the evolution of the system requires numerical solutions of the equations.

Such a model requires the testing of its reliability in various ways. It may be reasonable to stick to a terminology that seems to be established in the community: verification refers to the test of the numerical solution process and validation refers to the test with observed information on a real system (Oreskes et al. 1994; Thompson 1995; Bueler 2008)

Although the word verification stems from the Latin word for truth, verification is a matter of accuracy rather than truth. The word validation in turn should be interpreted as a test of reliability. Taking the words too literally may tempt one to declare the corresponding control as impossible (Oreskes et al. 1994), instead of taking them more pragmatically.

A third testing possibility are intercomparisons of models for the same system. Intercomparison projects became popular in many Earth system modelling sciences, in particular in glacier and ice sheet modelling (Huybrechts et al. 1997). Model intercomparisons may contain elements of both verification and validation. Verification (or falsification) may result if the models in comparison solve the equations with essentially different numerical methods (Pattyn et al. 2007), or if a verified benchmark is available.

The European Ice Sheet Modelling Initiative intercomparison revealed a common feature of all ice sheet models, the breaking of the cylindrical symmetry in the internal fields despite the radial symmetry in the boundary conditions (Payne et al. 2000). Interestingly, such a symmetry breaking does not show in models of realistic ice sheets or, perhaps, it is disguised in the fields with more variability. The intercomparison shows that all models display this symmetry breaking; however, the patterns vary between the models. Higher order mechanics does not reduce the symmetry breaking (Saito et al. 2006) and the specific shapes may also depend on initial conditions. A persistent pattern is that the spokes follow the grid lines and grid symmetry, except for very cold ice sheets, where irregularities emerge that do not follow the grid symmetry (A. Aschwanden, personal communication, September 2009).

The EISMINT intercomparison discovered (Payne et al. 2000), described (Payne and Baldwin 2000) and compared the spokes in various different models; however, they did not 
explain their physical or mathematical origin, except for some speculative interpretations (Payne and Dongelmans 1997). The emergence of the spoky patterns must be taken as an indication that the system of equations is vulnerable to ill condition and perhaps instability. Seemingly, the spokes only occur in the system with full thermomechanical coupling and free surface, and

derivative with respect to temperature of the strain-heating term (can be identified) as the controlling quantity in the spokes...

... local grid refinement near areas of maximum strain heating and/or smoothing of the strain heating term will ameliorate this problem (Bueler et al. 2005, 2006).

Recently, in the Heinrich Event INtercOmparison (HEINO) topic of the Ice-Sheet Model Intercomparison Project (ISMIP) internal large-scale ice sheet instabilities in different contemporary ice sheet models were explored (Calov et al. 2010). For the experiments, a simplified geometry that reproduces the main characteristics of the Laurentide ice sheet (including the sedimented region over Hudson Bay and Hudson Strait) and a temporally constant glacial climate were employed. It was found that all participating models (eight SIA models and one combined SIA/SSA model) are capable of producing Heinrichtype free oscillations if the boundary conditions are sufficiently favourable. However, the large differences between the results of different models (some are much more prone to produce oscillations than others) clearly showed that further model improvements are crucial for adequate, robust simulations of ice sheet instabilities.

\subsection{Glacier Models}

Land ice masses not connected to the Greenland and Antarctic ice sheets contribute less than $1 \%$ to the water locked in all ice sheets, ice caps and glaciers together (Table 1). Although glaciers may contribute to sea level rise by less than $0.5 \mathrm{~m}$, their impact is on the short term, decades to centuries, and more local.

The strain softening property of ice limits the ice thickness as a function of the horizontal extent and steepness of the glacier. Thus the geometric aspect ratio of glaciers is one to two orders of magnitude larger than that of ice sheets, and requires more accurate models than the shallow ice approximation to reliably predict the long term evolution of its volume and geometry.

The application of higher order approximations or the full Stokes formulation of the ice flow make the implementation of a glacier model more demanding. The solution of the governing equations requires numerical algorithms that may be computationally expensive. Furthermore, the coupling of the ice flow in longitudinal and transverse directions due to the stress gradients makes the influence of boundary conditions non-local. Basal sliding feeds back to the velocity field both in vertical and horizontal directions and thus is not defined by local basal conditions alone, in contrast to the shallow ice approximation.

Various glacier models using the full Stokes scheme for the ice flow were implemented to study a range of processes, and recently to study glacial systems. Three-dimensional models were implemented to investigate the confluence of glaciers in the Swiss Alps (Gudmundsson 1994a, 1999). Full Stokes flow models including thermodynamics (Zwinger and Moore 2009) and in addition a compressible firn rheology (Lüthi and Funk 2000; Zwinger et al. 2007) were applied to high altitude firn areas for dating bore hole locations.

On a time scale of decades to centuries, for the predicted climate warming, glaciers and ice caps likely contribute more to sea level rise than the large ice sheets. Missing 
information and prohibitive computation time prevents a reliable prediction of the change in ice volume in most glaciers with comprehensive models. However, the modelling of carefully chosen sample glaciers may give a background information for the behaviour of the multitude of glaciers.

The size of most glaciers falls short of the grid resolution of prognostic global climate models, but also of the resolution of local networks of meteorological stations. Furthermore, the local conditions in glacierised valleys or on ice caps may be influenced by the topography and the thermal conditions of the ice surface itself. Thus, downscaling of the projected climatic conditions is an important requirement.

A possible simplified downscaling is based on the assumption that in a changing climate the fields of temperature and precipitation have larger spatial variability than the fields of their corresponding changes over time. Thus, the observed present-day local conditions can be combined with the larger scale change of climatic conditions to generate a local climate scenario (Schneeberger et al. 2001, 2003). More sophisticated downscaling schemes range from statistical downscaling (see, e.g., Hofer et al. 2010, and references therein) to the nesting of comprehensive global and regional climate models (Christensen and Christensen 2007; Frei et al. 2007). The climate input can be transformed to a mass balance information using e.g. the temperature and radiation index model of Hock (1999), e.g., Jouvet et al. (2008) with measured meteorological data for the past decades or climate scenarios for the future.

\section{Conclusions and Prospects}

The seemingly high sensitivity of a glacial system is reflected in the high sensitivity of the combined problem of free surface flow and thermomechanical coupling. Thus, the prognostic power of ice sheet modelling depends crucially on reliable verification of the numerical methods used. However, the prognostic power may suffer from limited knowledge, either limited accuracy or even lack of information on internal processes (anisotropy, hydraulics, sliding, grounding line) and on the boundary conditions given from external systems (atmosphere, ocean, solid Earth). This is already the case for the ice sheet dynamics determined on the mass flux time scale by the smooth and continuous processes such as ice flow and climatological mass fluxes on the surface. Even more, this is true for processes determined by discontinuous processes that may lead to changes on the catastrophic time scale such as surges and ice shelf disintegration due to grounding line instabilities.

Computation power and efficiency of numerical methods have progressed to the point where full Stokes solutions for glaciers are obtainable on affordable computers. Threedimensional flow fields were computed diagnostically for the Gorshkov crater glacier, Kamchatka (Zwinger et al. 2007), including thermomechanical coupling and firn, and prognostically for Midtre Lovénbreen, Svalbard (Zwinger and Moore 2009). A threedimensional full Stokes model coupled to a novel scheme for solving the transport equation with a volume of fluid method was applied to Alpine glaciers (Jouvet et al. 2008; Jouvet et al. 2009). The above models apply a finite element method on unstructured grids. A three-dimensional full Stokes model solving the equations on a finite difference grid was applied to study the stability of subglacial lakes (Pattyn 2008).

The next logical steps in ice sheet model development may be anticipated by extrapolating recent developments and requirements for the future. The developments will likely include full Stokes solutions for entire ice sheets with adaptive grids to obtain high spatial 
resolution where required. They will apply novel solvers and pre-conditioners to increase computational efficiency and certainly faster computers. Currently, at least three projects started to develop the next generation ice sheet models (http://www.elmerfem.org/wiki/ index.php/Elmer_Ice_Sheet_modeling, http://issm.jpl.nasa.gov/, http://trac.mcs.anl.gov/ projects/sisiphus). This kind of engineering work requires close collaboration between specialists in various fields: physicists, mathematicians, computer scientists. However, the challenge will also be the identification of the right processes and their relevant physics to obtain truly conclusive answers to the pressing questions of the future of the ice sheets and their stability.

Acknowledgments We thank Prof. Lennart Bengtsson (Director Earth Science, International Space Science Institute, Bern, Switzerland) for the kind invitation to submit this review paper to Surveys in Geophysics. Scientific editor Prof. Johannes Oerlemans (Institute for Marine and Atmospheric Research, Utrecht University, The Netherlands) and two anonymous reviewers provided useful comments for improving the paper. Dr. Tracy Ewen (Department of Geography, University of Zurich, Switzerland) proofread the manuscript.

\section{References}

Abe-Ouchi A, Blatter H (1993) On the initiation of ice sheets. Ann Glaciol 18:203-207

Abe-Ouchi A, Segawa T, Saito F (2007) Climatic conditions for modelling the northern hemisphere ice sheets through the ice age cycle. Clim Past 3:423-438

Abramowitz M, Stegun IA (1970) Handbook of mathematical functions with formulars, graphs, and mathematical tables. Dover Publications, New York

Alley RB (1992) Flow-law hypotheses for ice-sheet modeling. J Glaciol 38(129):245-256

Anandakrishnan S, Catania GA, Alley RB, Horgan HJ (2007) Theoretical limitations to englacial velocity calculations. Science 315:1835-1841

Arthern RJ, Gudmundsson GH (2010) Initialization of ice-sheet forecast viewed as an inverse Robin problem. J Glaciol 56(197):527-533

Arthern RJ, Hindmarsh RCA (2006) Determining the contribution of Antarctica to sea-level rise using data assimilation methods. Phil Trans R Soc A 364:1841-1865

Bahr DB, Pfeffer WT, Meier MF (1994) Theoretical limitations to englacial velocity calculations. J Glaciol 40(136):509-518

Benn DI, Hulton NRJ, Mottram R (2007) 'Calving laws', 'sliding laws' and the stability of tidewater glaciers. Ann Glaciol 46:123-130

Bindoff NL, Willebrand J, Artale V, Cazenave A, Gregory J, Gulev S, Hanawa K, Le Quéré C, Levitus S, Nojiri Y, Shum CK, Talley LD, Unnikrishnan A (2007) Observations: oceanic climate change and sea level. In: Solomon S, Qin D, Manning M, Chen Z, Marquis M, Averyt KB, Tignor M, Miller HL (eds) Climate change 2007: the physical science basis. Contribution of working group I to the fourth assessment report of the intergovernmental panel on climate change. Cambridge University Press, Cambridge, pp 385-432, http://ipcc-wg1.ucar.edu/wg1/wg1-report.html

Blatter H (1995) Velocity and stress fields in grounded glaciers: a simple algorithm for including deviatoric stress gradients. J Glaciol 41(138):333-344

Box JE, Bromwich DH, Veenhuis BA, Bai L, Stroeve JC, Rogers JC, Steffen K, Haran T, Wang S (2006) Greenland ice sheet surface mass balance variability (1988-2004) from calibrated polar MM5 output. J Clim 19:2783-2800

Brotchie JF, Silvester R (1969) On crustal flexure. J Geophys Res 74(22):5240-5252

Bueler E (2008) Lessons from the short history of ice sheet model intercomparison. Cryosphere Discuss 2:399-412

Bueler E, Brown J (2009) Shallow shelf approximation as a "sliding law" in a thermomechanically coupled ice sheet model. J Geophys Res 114:F03008. doi:10.1029/2008JF001179

Bueler E, Kallen-Brown JA, Lingle C (2005) Exact solutions and the verification of numerical models for ice sheets. Poster, EGU General Assembly, Vienna, Austria http://www.gi.alaska.edu/snowice/glaciers/ iceflow/EGUposter.png

Bueler E, Brown J, Lingle C (2006) Verifying thermocoupled ice sheet models (and explaining the "warm spokes"). Presentation, 13th West Antarctic ice sheet workshop, Pack Forest, Washington http://www.gi.alaska.edu/snowice/glaciers/iceflow/Bueler_WAIS06.pdf 
Bueler E, Khroulev C, Aschwanden A, Joughin I, Smith BE (2010) Modeled and observed fast flow in the Greenland ice sheet. Poster, EGU General Assembly, Vienna, Austria http://www.gi.alaska.edu/snow ice/glaciers/iceflow/posterBKAJS.pdf

Calov R, Hutter K (1996) The thermomechanical response of the Greenland ice sheet to various climate scenarios. Clim Dyn 12:243-260

Calov R, Greve R, Abe-Ouchi A, Bueler E, Huybrechts P, Johnson JV, Pattyn F, Pollard D, Ritz C, Saito F, Tarasov L (2010) Results from the ice-sheet model intercomparison project-Heinrich event intercomparison (ISMIP HEINO). J Glaciol 56(197):371-383

Christensen JH, Christensen OB (2007) A summary of PRUDENCE model projection of changes in european climate by the end of theis century. Clim Change 81:7-30

Clausen M, Mysak LA, Weaver AJ, Crucifix M, Fichefet T, Loutre M, Weber SL, Alcamo J, Alexeev VA, Berger A, Calov R, Ganopolski A, Goosse H, Lohmann G, Lunkeit F, Mokhov II, Stone P, Wang Z (2002) Earth system models of intermediate complexity: closing the gap in the spectrum of climate system models. Clim Dyn 18:579-586

Cuffey KM, Paterson WSB (2010) The physics of glaciers, 4th edn. Elsevier, Amsterdam

Durand G, Gagliardini O, de Fleurian B, Zwinger T, Le Meur E (2009a) Marine ice sheet dynamics: hysteresis and neutral equilibrium. J Geophys Res 114(F3):F03009. doi:10.1029/2008JF001170

Durand G, Gagliardini O, Zwinger T, Le Meur E, Hindmarsh RCA (2009b) Full Stokes modeling of marine ice sheets: influence of the grid size. Ann Glaciol 50(52):109-114

Fowler AC (2001) Modelling the flow of glaciers and ice sheets. In: Straughan B, Greve R, Ehrentraut H, Wang Y (eds) Continuum mechanics and applications in geophysics and the environment. Springer, Berlin, pp 201-221

Frei C, Calanca P, Schär C, Wanner H, Schädler B, Haeberli W, Appenzeller C, Neu U, Thalmann E, Ritz C, Hohmann R (2007) Die Klimazukunft der Schweiz. In: Klimaänderung und die Schweiz 2050Erwartete Auswirkungen auf Umwelt, Gesellschaft und Wirtschaft, Beratendes Organ für Fragen der Klimaänderung OcCC, pp 12-16. http://www.occc.ch

Gagliardini O, Gillet-Chaulet F, Montagnat M (2009) A review of anisotropic polar ice models: from crystal to ice-sheet flow models. Low Temp Sci 68(Suppl.):149-166

Gagliardini O, Durand G, Zwinger T, Hindmarsh RCA, Le Meur E (2010) Coupling of ice-shelf melting and buttressing is a key process in ice-sheet dynamics. Geophys Res Lett 37(L14501). doi: 10.1029/2010GL043334

Ganopolski A, Calov R, Claussen M (2010) Simulation of the last glacial cycle with a coupled climate icesheet model of intermediate complexity. Clim Past 6:229-244

Gladstone RM, Lee V, Vieli A, Payne AJ (2009) Grounding line migration in an adaptive mesh ice sheet model. J Geophys Res 115(F04014). doi:10.1029/2009JF001615

Goldberg DN, Holland DM, Schoof CG (2009) Grounding line movement and ice shelf buttressing in marine ice sheets. J Geophys Res 114(F04026). doi:10.1029/2008JF001227

Goldsby DL, Kohlstedt DL (2001) Superplastic deformation of ice: experimental observations. J Geophys Res 106(B6):11017-11030

Greve R (1997) Application of a polythermal three-dimensional ice sheet model to the Greenland ice sheet: response to steady-state and transient climate scenarios. J Clim 10(5):901-918

Greve R (2000) On the response of the Greenland ice sheet to greenhouse climate change. Clim Change 46(3):289-303

Greve R, Blatter H (2009) Dynamics of ice sheets and glaciers. Advances in geophysical and environmental mechanics and mathematics. Springer, Berlin

Grosfeld K, Sandhäger H (2004) The evolution of a coupled ice shelf-ocean system under different climate states. Global Planet Change 42:107-132

Gudmundsson GH (1994a) Convergent glacier flow and perfect sliding over a sinusoidal bed. PhD thesis, ETH Zürich, no. 10711

Gudmundsson GH (1994b) Glacier sliding over sinusoidal bed and the characteristics of creeping flow over bedrock undulations. Mitteilung 130, Versuchsanstalt für Wasserbau, Hydrologie und Glaziologie der ETH Zürich

Gudmundsson GH (1999) A three-dimensional numerical model of the confluence area of unteraargletscher, bernese alps, switzerland. J Glaciol 45(150):219-230

Gudmundsson GH (2003) Transmission of basal variability to a glacier surface. J Geophys Res 108:B42253. doi:10.1029/2002JB002107

Gudmundsson GH (2008) Analytical analysis of small-amplitude perturbations in the shallow ice stream approximation. Cryosphere Discuss 2:23-74

Heimbach P, Bugnion V (2009) Greenland ice-sheet volume sensitivity to basal, surface and initial conditions derived from an adjoint model. Ann Glaciol 50(52):67-80 
Hindmarsh RCA (2004) A numerical comparison of approximations to the Stokes equations used in ice sheet and glacier modeling. J Geophys Res 109:F01,012

Hindmarsh RCA (2006) Paradoxes and problems with the longitudinal stress approximations used in glacier mechanics. GAMM-Mitt 29(1):52-79

Hindmarsh RCA (2006) The role of membrane-like stresses in determining the stability and sensitivity of the Antarctic ice sheet: back pressure and grounding line motion. Phil Trans R Soc A 364:1733-1767

Hock R (1999) A distributed temperature-index ice and snowmelt model including potential direct solar radiation. J Glaciol 45(149):101-111

Hofer M, Mölg T, Marzeion B, Kaser G (2010) Empirical-statistical downscaling of reanalysis data to highresolution air temperature and specific humidity above a glacier surface (Cordilliera Blanca, Peru). J Geophys Res D12120. doi:10.1029/2009JD012556

Hooke RL (2005) Principles of glacier mechanics, 2nd edn. Cambridge University Press, Cambridge

Horgan HJ, Anandakrishnan S (2006) Static grounding lines and dynamic ice streams: evidence from the Siple Coast, West Antarctica. Geophys Res Lett 33:L18502

Hutter K (1983) Theoretical glaciology; material science of ice and the mechanics of glaciers and ice sheets. D. Reidel Publishing Company, Dordrecht

Huybrechts P (1990) A 3-D model for the Antarctic ice sheet: a sensitivity study on the glacial-interglacial contrast. Clim Dyn 5:79-92

Huybrechts P (1996) Basal temperature conditions of the Greenland ice sheet during the glacial cycles. Ann Glaciol 23:226-236

Huybrechts P, Payne T, the EISMINT Intercomparison Group (1997) The EISMINT benchmarks for testing ice-sheet models. Annals Glaciol 23:1-12

IPCC (2007) Summary for policymakers. In: Solomon S, Qin D, Manning M, Chen Z, Marquis M, Averyt KB, Tignor M, Miller HL (eds) Climate change 2007: the physical science basis. Contribution of working group I to the fourth assessment report of the intergovernmental panel on climate change. Cambridge University Press, Cambridge, pp 1-18

Jenkins A, Bombosch A (1995) Modeling the effects of frazil ice crystals on the dynamics and thermodynamics of ice shelf water plumes. J Geophys Res 100:6967-6981

Joughin I, MacAyeal D (2005) Calving of large tabular icebergs from ice rift systems. Geophys Res Lett 32:L02, 501

Joughin I, Howat IM, Fahnestock M, Smith B, Krabill W, Alley RB, Stern H, Truffer M (2008) Continued evolution of Jakobshavn Isbrae following its rapid speedup. J Geophys Res 113:F04,006

Jouvet G (2010) Modélisation, analyse mathématique et simulation numérique de la dynamique des glaciers. $\mathrm{PhD}$ thesis, Ecole Polytechnique Fédérale de Lausanne

Jouvet G, Picasso M, Rappaz J, Blatter H (2008) A new algorithm to simulate the dynamics of a glacier: theory and applications. J Glaciol 54(188):801-811

Jouvet G, Huss M, Blatter H, Picasso M, Rappaz J (2009) Numerical simulations of Rhohnegletscher from 1874 to 2100. J Comp Phys 228:6426-6439

Kachanov LM (1999) Rupture time under creep conditions. Int J Fract 97(1-4):xi-xviii (translation from Izv. Akad. Nauk. SSSR, Itd. Tekh. Nauk. Metall. Topl., 8, 26-31, 1957)

Krajcinovic D (1996) Damage mechanics. Elsevier, New york

Krimmel RM (2001) Photogrammetric data set, 1957-2000, and bathymetric measurements for Columbia Glacier, Alaska. Water Resour. Invest. Rep. 014089, U.S. Geol. Surv

Lambeck K, Johnston P, Nakada M (1990) Holocene glacial rebound and sea-level change in NW Europe. Geophys J Int 103:451-468

Langdon TG (1996) Transitions in creep behavior. Mater Trans Jpn Inst Metal 37(3):359-362

Le Meur E (1996) Isostatic postglacial rebound over Fennoscandia with a self-gravitating spherical viscoelastic Earth model. Ann Glaciol 23:318-327

Le Meur E, Huybrechts P (1996) A comparison of different ways of dealing with isostasy: examples from modelling the Antarctic ice sheet during the last glacial cycle. Ann Glaciol 23:309-317

Le Meur E, Huybrechts P (2001) A model computation of the temporal changes of surface gravity and geoidal signal induced by the evolving Greenland ice sheet. Geophys J Int 145:835-849

Lemke P, Ren J, Alley RB, Allison I, Carrasco J, Flato G, Fujii Y, Kaser G, Mote P, Thomas RH, Zhang T (2007) Observations: changes in snow, ice and frozen ground. In: Solomon S, Qin D, Manning M, Chen Z, Marquis M, Averyt KB, Tignor M, Miller HL (eds) Climate change 2007: the physical science basis. Contribution of working group I to the fourth assessment report of the intergovernmental panel on climate change. Cambridge University Press, Cambridge, pp 337-383. http://ipcc-wg1.ucar.edu/ wg1/wg1-report.html

Lewis EL, Perkin RG (1986) Ice pumps and their rates. J Geophys Res 91(C10):11756-11762 
Lüthi M, Funk M (2000) Dating ice cores from a high Alpine glacier with a flow model for cold firn. Ann Glaciol 31:69-79

Marguerre K, Woernle HT (1969) Elastic plates. Blaisdell Publishing Company, Waltham

Meehl GA, Stocker TF, Collins WD, P F, Gaye AT, Gregory JM, Kitoh A, Knutti R, Murphy JM, Noda A, Raper SCB, Watterson IG, Weaver AJ, Zhao ZC (2007) Global climate projections. In: Solomon S, Qin D, Manning M, Chen Z, Marquis M, Averyt KB, Tignor M, Miller HL (eds) Climate change 2007: the physical science basis. Contribution of working group I to the fourth assessment report of the intergovernmental panel on climate change. Cambridge University Press, Cambridge, pp 747-845. http://ipcc-wg1.ucar.edu/wg1/wg1-report.html

Morland LW (1984) Thermomechanical balances of ice sheet flows. Geophys Astrophys Fluid Dyn 29:237-266

Morland LW (1987) Unconfined ice-shelf flow. In: Veen CJ, Oerlemans J (eds) Dynamics of the West Antarctic ice sheet. D. Reidel Publishing Company, Dordrecht, pp 99-116

Murray AB (2002) Seeking explanation affects numerical modeling strategies. EOS Trans AGU 83:418-419

Nick FM, van der Veen CJ, Oerlemans J (2007) Controls on advance of tidewater glaciers: results from numerical modeling applied to Columbia Glacier. J Geophys Res 112:F03S24. doi:10.1029/ 2006JF000551

Nick FM, van der Veen CJ, Vieli A, Benn DI (2010) A physically based calving model applied to marine outlet glaciers and implications for the glacier dynamics. J Glaciol 56(199):781-794

Nøst OA, Foldvik A (1994) A model of ice shelf-ocean interaction with application to the Filchner-Ronne and Ross ice shelves. J Geophys Res 99(C7):14243-14254

Nye JF (1957) The distribution of stress and velocity in glaciers and ice-sheets. Proc R Soc Lond Ser A 239(1216):113-133

Ohmura A (2010) Mass balance of glaciers and ice sheets during the observational period and climate change (in japanese). J Geogr Tokyo Geogr Soc 119(3):466-481

Oreskes N, Shrader-Frechette K, Belitz K (1994) Verification, validation, and confirmation of numerical models in the earth sciences. Science 263:641-646

Otero J, Navarro FJ, Martin C, Cuadrado ML, Corcuera MI (2010) A three-dimensional calving model: numerical experiments on Johnsons Glacier, Livingston Island, Antarctica. J Glaciol 56(196):200-214

Paterson WSB (1994) The physics of glaciers, 3rd edn. Pergamon Press, Oxford

Pattyn F (2008) Investigating the stability of subglacial lakes with a full Stokes ice-sheet model. J Glaciol 54(185):353-361

Pattyn F et al (2007) Benchmark experiments for higher-order and full Stokes ice sheet models (ISMIPHOM). Cryophere 2:95-108. doi:10.5194/tc-2-95-2008

Payne AJ, Baldwin DJ (2000) Analysis of ice-flow instabilities identified in the EISMINT intercomparison exercise. Annals Glaciol 30:204-210

Payne AJ, Dongelmans PW (1997) Self-organization in the thermomechanical flow of ice sheets. J Geophys Res 102(B6):12219-12233

Payne AJ, Huybrechts P, Abe-Ouchi A, Calov R, Fastook JL, Greve R, Marshall S, Marsiat I, Ritz C, Tarasov L, Thomassen MPA (2000) Results from the EISMINT model intercomparison: the effects of thermomechanical coupling. J Glaciol 46(153):227-238

Payne AJ, Vieli A, Shepherd AP, Wingham DJ, Rignot E (2004) Recent dramatic thinning of largest West Antarctic ice stream triggered by oceans. Geophys Res Lett 31:L23, 401

Pettit EC, Waddington ED (2003) Ice flow at low deviatoric stress. J Glaciol 49(166):359-369

Pralong A, Funk M (2005) Dynamic damage model of crevasse opening and application to glacier calving. J Geophys Res 110:B01309. doi:10.1029/2004JB003104

Pralong A, Funk M, Lüthi MP (2003) A description of crevasse formation using continuum damage mechanics. Ann Glaciol 37:77-82

Pralong A, Hutter K, Funk M (2006) Anisotropic damage mechanics for viscoelastic ice. Cont Mech Thermodyn 17(5):387-408. doi:10.1007/s00161-005-0002-5

Ridley JK, Gregory JM, Huybrechts P, Lowe JA (2009) Thresholds for irreversible decline of the Greenland ice sheet. Clim Dyn. doi:10.1007/s00382-009-0646-0

Rignot E, Steffen K (2008) Channelized bottom melting and stability of floating ice shelves. Geophys Res Lett 35:L02,503

Ritz C (1987) Time dependent boundary conditions for calculation of temperature fields in ice sheets. In: Waddington ED, Walder JS (eds) The physical basis of ice sheet modelling. IAHS Publication No. 170, IAHS Press, Wallingford, pp 207-216

Ritz C, Fabre A, Letréguilly A (1997) Sensitivity of a Greenland ice sheet model to ice flow and ablation parameters: consequences for the evolution through the last climatic cycle. Clim Dyn 13(1):11-24 
Ritz C, Rommelaere V, Dumas C (2001) Modeling the evolution of Antarctic ice sheet over the last 420,000 years: implications for altitude changes in the Vostik region. J Geophys Res 106(D23): 31943-31964

Rogozhina I, Martinec Z, Hagedorn JM, Thomas M (2011) On the long-term memory of the Greenland ice sheet. J Geophys Res 116:F01011. doi:10.1029/2010JF001787

Saito F, Abe-Ouchi A (2004) Thermal structure of Dome Fuji and east Dronning Maud Land, Antarctica, simulated by a three-dimensional ice-sheet model. Ann Glaciol 39:433-438

Saito F, Abe-Ouchi A, Blatter H (2006) European ice sheet modelling initiative (EISMINT) model intercomparison experiments with first order mechanics. J Geophys Res 111:F02012

Scambos T, Fricker HA, Liu C, Bohlander J, Fastook J, Sargent A, Massom R, Wu A (2009) Ice shelf disintegration by plate bending and hydro-fracture: satellite observations and model results of the 2008 Wilkins ice shelf break-up. Earth Planet Sci Lett 280:51-60

Schneeberger C, Albrecht O, Blatter H, Wild M, Hock R (2001) Modelling the response of glaciers to a doubling in atmospheric $\mathrm{CO}_{2}$ : a case study on Storglaciären, northern Sweden. Clim Dyn 17(11):825-834

Schneeberger C, Blatter H, Abe-Ouchi A, Wild M (2003) Modelling changes in the mass balance of glaciers of the northern hemisphere for a transient $2 \mathrm{xCO}_{2}$ scenario. J Hydrol 282(1-4):145-163

Schoof C (2007) Ice sheet grounding line dynamics: steady states, stability, and hysteresis. J Geophys Res 112:F03S28. doi:10.1029/2006JF000664

Schoof C, Hindmarsh RCA (2010) Thin-film flows with wall slip: an asymptotic analysis of higher order glacier flow. Q J Mech Appl Math 63(1):73-114. doi:10.1093/qjmam/hbp025

Smedsrud LH, Jenkins A (2004) Frazil ice formation in an ice shelf water plume. J Geophys Res 109:C03, 025

Tarasov L, Peltier WR (2002) Greenland glacial history and local geodynamic consequences. Geophys J Int 150(1):198-229

Thoma M, Wolf D (1999) Bestimmung der Mantelviskosität aus Beobachtungen der Landhebung und Schwere in Fennoskandien. Scientific Technical Report STR99/02, GeoForschungsZentrum Potsdam, Germany

Thompson DE (1995) Verification, validation, and solution quality in computational physics: Cfd methods applied to ice sheet physics. Tech. rep., NASA/TM-2005-213453, NASA, Ames Research Center

Truffer M (2004) The basal speed of valley glaciers: an inverse approach. J Glaciol 50(169):236-242

Vander Veen CJ (1996) Tidewater calving. J Glaciol 42:375-385

Verbitsky M (2002) Siple coast ice streams in a General Antarctic ice sheet model. J Clim 18:2194-2198

Vieli A, Payne AJ (2003) Application of control methods for modelling the flow of Pine Island Glacier, West Antarctica. Ann Glaciol 36:197-204

Vieli A, Payne AJ (2005) Assessing the ability of numerical ice sheet models to simulate grounding line migration. J Geophys Res 110:1815-1839. doi:10.1029/2004JF000202

Vieli A, Funk M, Blatter H (2000) Tidewater glaciers: frontal flow acceleration and basal sliding. Ann Glaciol 31:217-221

Vieli A, Funk M, Blatter H (2001) Flow dynamics of tidewater glaciers: a numerical modelling approach. J Glaciol 47(159):595-606

Vieli A, Jania J, Kolondra L (2002) The retreat of a tidewater glacier: observations and model calculations on Hansbreen, Spitsbergen. J Glaciol 48(163):592-600

Vieli A, Payne AJ, Du Z, Shepherd A (2006) Numerical modelling and data assimilation of the Larson B ice shelf, Antarctic Peninsula. Phil Trans R Soc A 364:F01003. doi:10.1098/rsta.2006.1800

Vizcaíno M, Mikolajewicz U, Gröger M, Maier-Reimer E, Schurgers G, Winguth AME (2008) Long-term ice sheet-climate interactions under anthropogenic greenhouse forcing simulated with a complex Earth System Model. Climate Dyn 31(6):665-690. doi:10.1007/s00382-008-0369-7

Walker RT, Dupont TK, Parizek BR, Alley RB (2008) Effect of basal-melting distribution on the retreat of ice-shelf grounding lines. Geophys Res Lett 35(L17503). doi:10.1029/2008GL034947

Walker RT, Dupont TK, Holland DM, Parizek BR, Alley RB (2009) Initial effects of oceanic warming on a coupled ocean-ice shelf-ice stream system. Earth Planet Sci Lett 287:483-487

Weertman J (1957) On the sliding of glaciers. J Glaciol 3(21):33-38

Weertman J (1964) The theory of glacier sliding. J Glaciol 5(39):287-303

Weertman J (1971) In defence of a simple model of glacier sliding. J Geophys Res 76(26):6485-6487

Weis M, Greve R, Hutter K (1999) Theory of shallow ice shelves. Continuum Mech Thermodyn 11(1):15-50

Zwinger T, Moore JC (2009) Diagnostic and prognostic simulations with a full Stokes model accounting for superimposed ice of Midtre Lovénbreen, Svalbard. Cryosphere 3:217-229

Zwinger T, Greve R, Gagliardini O, Shiraiwa T, Lyly M (2007) A full-Stokes thermo-mechanical model for firn and ice applied to the Gorshkov crate glacier, Kamchatka. Ann Glaciol 45:29-37 